\title{
Distributed but Convergent Ordering of Corticostriatal Projections: Analysis of the Frontal Eye Field and the Supplementary Eye Field in the Macaque Monkey
}

\author{
H. B. Parthasarathy, ${ }^{1}$ J. D. Schall, ${ }^{2}$ and A. M. Graybiel ${ }^{1}$ \\ 'Department of Brain and Cognitive Sciences, Massachusetts Institute of Technology, Cambridge, Massachusetts 02139 \\ and ${ }^{2}$ Department of Psychology, Vanderbilt University, Nashville, Tennessee 37240
}

The degree of parallel processing in frontal cortex-basal ganglia circuits is a central and debated issue in research on the basal ganglia. To approach this issue directly, we analyzed and compared the corticostriatal projections of two principal oculomotor areas of the frontal lobes, the frontal eye field (FEF) and the supplementary eye field (SEF). We first identified cortical regions within or adjacent to each eye field by microstimulation in macaque monkeys and then injected each site with either ${ }^{35}$ S-methionine or WGA-HRP conjugate. We analyzed the corticostriatal projections and also the interconnections of the pairs of cortical areas.

We observed major convergence of the projections of the FEF and the SEF within the striatum, principally in the caudate nucleus. In cross sections through the striatum, both projections were broken into a series of discontinuous input zones that seemed to be part of complex three-dimensional labyrinths. Where the FEF and SEF projection fields were both present, they overlapped patch for patch. Thus, both inputs were dispersed within the striatum but converged with one another. Striatal afferents from cortex adjacent to the FEF and the SEF did not show convergence with SEF and FEF inputs, but did, in part, converge with one another. For all pairs of cortical areas tested, the degree of overlap in the corticostriatal projections appeared to be directly correlated with the degree of cortical interconnectivity of the areas injected. All of the corticostriatal fiber projections observed primarily avoided immunohistochemically identified striosomes. We conclude that there is convergence of oculomotor information from two distinct regions of the frontal cortex to the striatal matrix, which is known to project into pallidonigral circuits including the striatonigrocollicular pathway of the saccadic eye movement system. Furthermore, functionally distinct premotor areas near the oculomotor fields often systematically projected to striatal zones adjacent to

\footnotetext{
Received Apr., 3, 1992; revised May 27, 1992; accepted June 9, 1992.

We thank H. F. Hall, who was responsible for the photography; D. Major and G. Holm for help with histology and immunohistochemistry; N. Logothetis, E. J. Tehovnik, K.-M. Lee, and A. W. Flaherty for help with the microstimulation phase of the experiments; E. J. Tehovnik, K.-M. Lee, and P. H. Schiller for contributing monkey M7;R. P. Flde for his gift of met-enkephalin antiserum; and M. Kimura for valuable discussion of our results. We also thank D. King as well as $\mathrm{A}$. Morel and I. Stepniewska for assistance in the two cases done at Vanderbilt. H.B.P. is supported by NIMH Training Grant T32MH15761. J.D.S. is a Kennedy Center Investigator, supported by EYO8890 and an Alfred P. Sloan fellowship. This work was supported by NIH Grant EY02866.

Correspondence should be addressed to Ann M. Graybiel, E25-618, M.I.T., 77 Massachusetts Avenue, Cambridge, MA 02139.

Copyright $(\mathcal{C} 1992$ Society for Neuroscience $0270-6474 / 92 / 124468-21 \$ 05.00 / 0$
}

oculomotor field projections, suggesting an anatomical basis for potential interaction of these inputs within the striatum. We propose that parallel processing is not the exclusive principle of organization of forebrain circuits associated with the basal ganglia. Rather, patterns of both convergence and divergence are present and are likely to depend on multiple functional and developmental constraints.

Theories about basal ganglia function have increasingly emphasized a parallel design of pathways emerging from the cortex, passing through the basal ganglia and returning to the cortex. Somatic motor, oculomotor, and complex loops have been distinguished for the frontal lobe's connections with the basal ganglia, and comparable parallel circuits have been hypothesized for other cortical domains (Graybiel, 1984; Alexander et al., 1986). Clear examples of convergence of corticostriatal input systems have been found (Yeterian and Van Hoesen, 1978; Flaherty and Graybiel, 1991a), and the anatomical studies suggest that projections from widely separated striatal neurons may converge on the same pallidal dendrites (Percheron et al., 1984). Thus, convergence may also be an important ordering principle, at least for basal ganglia circuits involving somesthesis (Flaherty and Graybiel, 1991a; Percheron and Filion, 1991). In the experiments reported here, we set out to examine these issues of convergence and nonconvergence by analyzing and comparing the patterns of projections to the striatum from two oculomotor fields of the frontal lobe.

The oculomotor system has major advantages as a test system for models of corticostriatal processing. First, physiological and anatomical evidence has strongly implicated regions of the striatum in the control of eye movements. In monkeys trained to perform tasks requiring saccadic eye movements, neurons in the caudate nucleus discharge in relation to intentional saccades (Hikosaka et al., 1989a), and in the substantia nigra pars reticulata, which receives input from the caudate nucleus, neuronal activity is also modulated during specific oculomotor tasks ranging from visually triggered to memory-guided saccades (Hikosaka and Wurtz, 1983a,b). The modulation of neuronal activity in the nigral pars reticulata is an inhibition of tonic activity that mirrors the excitation produced in the caudate nucleus. It is thought that the nigral neurons exert a tonic inhibitory effect on saccade-related neurons in the superior colliculus, and that this tonic nigrotectal inhibition can be relieved by striatal inhibition of the nigral neurons during the generation of saccades (Hikosaka and Wurtz, 1985a,b; Chevalier and Deniau, 1990). 
Thus, there is a discrete, functionally characterized, saccaderelated circuit running through the basal ganglia with a wellmapped representation in the striatum.

Second, previous work has shown that the two principal oculomotor fields of the frontal lobes, the medially located supplementary eye field (SEF) (Huerta and Kaas, 1990; Shook et al., 1991) and the laterally located frontal eye field (FEF) (Stanton et al., 1988), project strongly and discretely to a region of the caudate nucleus known to contain units with oculomotor properties. There are important differences in the activity profiles of neurons in the two cortical fields. Microstimulation of the FEF elicits vector-coded saccades (Robinson and Fuchs, 1969; Bruce and Goldberg, 1985), whereas the SEF can be stimulated to produce saccades with amplitudes and directions that are dependent on eye position (Schlag and Schlag-Rey, 1987; Tehovnik and Lee, 1990). Recording studies in monkeys trained to make saccades have shown that in the FEF, neurons fire before, during, and after saccades of a specific direction and amplitude (Bizzi and Schiller, 1970; Bruce and Goldberg, 1985; Schall, 1991b). Furthermore, in dorsomedial cortex, which probably includes the supplementary motor area (SMA) as well as the SEF, neurons have been found that fire during saccades to a given location in space (Lee and Tehovnik, 1991; Schall, 1991a). Thus, the cortical areas providing input to the oculomotor striatum have different processing parameters, and may even map oculomotor functions in different coordinate frames.

Third, these two oculomotor cortical fields are physically distant from one another, but are reciprocally interconnected (Huerta and Kaas, 1990; Schall et al., 1991). Thus, their cortico-striatal projections provide an excellent system for testing the hypothesis that corticocortical and corticostriatal connectivity patterns are lawfully related (Yeterian and Van Hoesen, 1978).

We therefore carried out a series of experiments designed to compare the corticostriatal projections from the SEF and the FEF. To define the SEF and FEF cortex, we applied the technique of cortical microstimulation in ketamine-anesthetized monkeys. Then, combining dual-tracer tract tracing with immunohistochemistry, we examined the patterns of corticostriatal innervation with respect to each other and to the striosomematrix compartmentalization of the striatum. In order to gain information about the more general topographic ordering of corticostriatal projections from the supplementary motor cortex and the periarcuate cortex, we also made tracer injections in regions adjacent to the two eye fields.

\section{Materials and Methods}

Cortical microstimulation and injection experiments were carried out on eight macaque monkeys (six Macaca fascicularis and two Macaca mulatta). In six monkeys, paired deposits of the distinguishable tracers ${ }^{35}$ S-methionine ( $200 \mu \mathrm{Ci} / \mu \mathrm{l}$; New England Nuclear) and wheat germ agglutinin-horseradish peroxidase (WGA-HRP; 15\% in saline; Sigma) were placed in the medial and lateral eye felds identified by stimulation, or in adjoining cortex (see Results). In one monkey (M4), paired injections of the two tracers werc made in topographically distinct regions of the FEF. In one other monkey (M7), WGA-HRP was injected into the dorsomedial frontal cortex mapped for saccade-related activity under alert behaving conditions (Tehovnik and Lee, 1990; this animal is also monkey Q reported in Schall, 1991a). Injection sites and volumes for the tracer deposits in each animal are summarized in Table 1.

Cortical microstimulation. Prior to surgery, each animal was tranquilized with ketamine $(12 \mathrm{mg} / \mathrm{kg})$ and anesthetized with xylazine $(0.7$ $\mathrm{mg} / \mathrm{kg})$. In addition, atropine $(0.04 \mathrm{mg} / \mathrm{kg})$, dexamethasone $(0.1 \mathrm{mg} / \mathrm{kg})$, and tribrissin $(30 \mathrm{mg} / \mathrm{kg})$ were administered. Anesthesia was maintained by ketamine (in doses of $5 \mathrm{mg} / \mathrm{kg}$ ) and supplemented, before surgical
Table 1. Summary of experimental protocols

\begin{tabular}{lllcr} 
& & & \multicolumn{2}{c}{ Tracer injections } \\
\cline { 4 - 5 } Case & Cortical area & Tracer & Number & Amount \\
\hline M1* & SEF & met & 1 & $40 \mathrm{nl}$ \\
& FEF & HRP & 2 & $40 \mathrm{nl}$ \\
M2 & pre-SMA & met & 1 & $200 \mathrm{nl}$ \\
& FEF & HRP & 1 & $200 \mathrm{nl}$ \\
M3 & pre-SMA & HRP & 1 & $18.2 \mathrm{nl}$ \\
& FEF & met & 1 & $17.5 \mathrm{nl}$ \\
M4 & FEF(d) & met & 1 & $70 \mathrm{nl}$ \\
& FEF(v) & HRP & 1 & $70 \mathrm{nl}$ \\
M5 & SEF & HRP & 6 & $40 \mathrm{nl}$ \\
& FEF(+d.arc.) & met & 18 & $40 \mathrm{nl}$ \\
M6 & SMA & HRP & 7 & $150 \mathrm{nl}$ \\
& arcuate & met & 7 & $150 \mathrm{nl}$ \\
M7* & DMFC & HRP & 20 & $200 \mathrm{nl}$ \\
M8 & SEF(+medial) & met & 1 & $15 \mathrm{nl}$ \\
& FEF & HRP & 3 & $7-14 \mathrm{nl}$ \\
\hline
\end{tabular}

Asterisks $\left({ }^{*}\right)$ indicate Macaca mulatta; all other monkeys were Macaca fascicularis. d, dorsal; v, ventral; arc., arcuate sulcus; SMA, supplementary motor area; SEF, supplementary eye field; FEF, genual frontal eye field (unless specified otherwise; see Results and figures for further description of the cortical areas injected); met, ${ }^{35}$ S-methionine; HRP, WGA-conjugated HRP.

procedures, by xylazine $(0.7 \mathrm{mg} / \mathrm{kg})$. Lactated Ringer's solution with $5 \%$ dextrose $(2.3 \mathrm{ml} / \mathrm{kg} / \mathrm{hr}$, i.v.) was given throughout the experiment.

In preparation for stimulation, the left frontal convexity cortex was exposed under sterile surgical conditions by removal of a bone flap. A metal post was cemented to the skull to provide painless restraint and head support without stereotaxic ear bars. The FEF and the SEF were located by monitoring cyc movements visually during intracortical microstimulation. Stimulus trains (cathodal, $0.2 \mathrm{msec}$ pulse width, 300 $\mathrm{Hz}$ ) were delivered for 50-100 msec through low-impedance (0.5-1.0 $\mathrm{M} \Omega$ ) glass-coated, platinum-iridium microelectrodes. Currents ranged from 30 to $100 \mu \mathrm{A}$ at most sites. Apparently because of difficulties in maintaining the same level of anesthesia throughout the physiological mapping phase of the experiments, higher currents were sometimes needed to elicit any movements whatsoever. Such sites are indicated on the maps generated.

Sites of electrode penetrations were marked on an enlarged photograph of the exposed cortex. To locate the FEF, we stimulated along the anterior lip of the arcuate sulcus and in adjoining cortex. To locate the SEF, we stimulated along the dorsomedial edge of the convexity cortex, starting at approximately the same anteroposterior level as the FEF and mapping rostrally and caudally, as well as medially and laterally. We tried to identify the rostral part of the SMA by monitoring upper body and head movements in response to the cortical microstimulation. Because eye movements were monitored visually, and also because ketamine may disrupt the oculomotor neural integrator (in cats; Godaux et al., 1990), the SEF and the FEF defined here are probably biased toward regions from which relatively large saccades can be elicited.

Tracer injections. In all but one experiment (M7), tracers were introduced into the cortex through glass micropipettes at sites determined during the mapping session and identified by reference to the photographic print on which stimulation sites were marked. The micropipettes were attached to a pressure-injection system (Picopump, World Precision Instruments) capable of delivering tracer in aliquots as small as 12 nl. In casc M7, traccr injections wcre made with a Hamilton syringe that was held in the same well used for chronic microelectrode recording studies performed on that animal (Tehovnik and Lee, 1990). Injection sizes were varied between $\sim 15-200 \mathrm{nl}$ of WGA-HRP or ${ }^{35} \mathrm{~S}$-methionine at each of the sites within each cortical area (Table 1).

Tissue preparation and histology. Following $\sim 48 \mathrm{hr}$ survival times, the monkeys were deeply anesthetized with ketamine (average, $16 \mathrm{mg}$ ) $\mathrm{kg}$ ) followed by Nembutal (average, $20 \mathrm{mg} / \mathrm{kg}$ ) and were perfused transcardially with $4 \%$ paraformaldehyde in $0.1 \mathrm{M} \mathrm{PO}_{4}$ buffer containing $0.9 \%$ saline. Brains were photographed and blocked in the transverse or midsagittal plane, and the blocks, after being soaked in buffer con- 
taining 20-30\% sucrose or glycerol, were cut on a freezing microtome at $40 \mu \mathrm{m}$ in coronal or sagittal sections. Sections were processed in serially adjacent sets for autoradiography, WGA-HRP histochemistry, and enkephalin immunohistochemistry.

For autoradiography, sections were mounted on chrome-alum-subbed slides, dried, defatted, dipped in Kodak NTB-2 emulsion, dried again, and stored in light-tight boxes at $-20^{\circ} \mathrm{C}$ for $1-8$ weeks. The exact exposure times were estimated by trials, and typically, series of sections were prepared at different exposure times for each case. Sections were developed in Kodak D19 developer and counterstained through the emulsion. WGA-HRP histochemistry was carried out by Mesulam's tetramethyl benzidine (TMB) method (Mesulam, 1978) with the modification that the incubation solutions were changed every $3 \mathrm{~min}$ to decrease accumulation of artifact (llling and Graybiel, 1985). Immunohistochemistry with a polyclonal met-enkephalin antiserum (kind donation of Dr. R. P. Elde, Department of Cell Biology and Neuroanatomy, University of Minnesota) was carried out to demonstrate striosomes (Graybiel and Chesselet, 1984). Either the avidin-biotin or the peroxidase-antiperoxidase method was followed after treatment of the sections with $10 \%$ methanol and $3 \% \mathrm{H}_{2} \mathrm{O}_{2}$ to eliminate cross-reaction with WGA-HRP and to inhibit endogenous peroxidases.

Data analysis. Sites of microstimulation and sites of tracer injections were mapped onto reconstructions of the frontal cortex made with the aid of the photographs taken at the time of mapping and after perfusion. Borders of effective injection sites, including central zones and surrounding regions of weaker labeling, were determined by eye according to the intensity of tracer visible. Sections were viewed with dark-field and light-field optics and, for WGA-HRP, with cross-polarized darkfield illumination (Illing and Wässle, 1979). Patterns of transported anterograde tracer labeling were charted with the aid of a drawing tube in serial sets of sections processed for autoradiography and for WGAHRP, and striosomes in adjoining sets of sections stained for enkephalin-like immunoreactivity were also charted. Charts of adjacent sections were aligned according to local vascular landmarks, and the distributions of the anterograde tracers were plotted with respect to each other and to the location of striosomes visible as zones of reduced perikaryal enkephalin immunostaining relative to the surrounding matrix. Charts were also madc of transcortical conncctions. Bccausc the TMB reaction was susceptible to artifact from tissue damage along the pipette tracks, it was often impossible to chart reliably the anterograde WGA-HRP labeling in and near the ${ }^{35}$ S-methionine injection sites. Judgements of interconnectivity, therefore, typically were made on the basis of one corticocortical direction, that is, in the anterograde direction from the ${ }^{35} \mathrm{~S}$-methionine injection, and all illustrations of cortical connectivity are shown for this direction only. Mention of intracortical transport of WGA-HRP is made in the text where possible.

\section{Results}

Repeated microstimulation at any one site in the cortex anterior to the arcuate sulcus elicited contraversive saccadic eye movements that appeared qualitatively similar to one another, and longer stimulus trains elicited "staircase saccades." No other obvious movements accompanied these saccades. As documented in previous studies of this area (Robinson and Fuchs, 1969; Bruce and Goldberg, 1985), a progression of larger to smaller saccades was found as the stimulating electrode was moved from medial (anterior) to more lateral (posterior) sites along the anterior bank of the arcuate sulcus. We identified as the FEF a discrete region, usually found immediately anterior to the arcuate genu, from which this pattern of saccades could be elicited with microstimulation currents under $50 \mu \mathrm{A}$. Microstimulation of prearcuate cortex along the upper limb of the arcuate sulcus, rostral to the FEF so defined, also elicited saccades (Robinson and Fuchs, 1969). However, these saccades had larger thresholds and were often accompanied by ear or neck movements. It has recently been reported that a region at the fundus of the arcuate cortex is involved in the control of smooth-pursuit eye movements (MacAvoy et al., 1991). We did not identify such an area, but it is possible that the deepest FEF tracer injections encroached on this territory.
Microstimulation of the cortex along the dorsomedial part of the frontal convexity cortex, in the expected region of the SEF, elicited eye movements less reliably than microstimulation of the arcuate cortex. Considerable mapping, over as much as 10$15 \mathrm{~mm}$ anteroposteriorly and $5 \mathrm{~mm}$ or more mediolaterally, was often required to identify a discrete eye movement field. The lowest currents used for microstimulation were $50 \mu \mathrm{A}$. In six monkeys (M1, M2, M3, M5, M8, M9), we identified relatively circumscript medial convexity cortex within which microstimulation elicited contraversive saccades. The saccadic response often habituated with repeated stimulation, and it typically was accompanied by movements of the ear and facial muscles, even at sites with very low movemenl-evoking thresholds. In most of the monkeys, the medial eye field so identified seemed to correspond to the SEF as originally described by Schlag and Schlag-Rey in the macaque (1987): it lay just anterior to cortex in which upper body and head movements could be triggered by microstimulation, and it was several millimeters medial but only slightly anterior to the FEF. We considered this region to be the SEF. In one monkey (M3), the region from which we elicited saccades lay farther anterior, as documented below.

In the course of our experiments, we injected (1) the FEF and the SEF, as defined by low-threshold microstimulation; (2) the dorsal limb of the arcuate sulcus (from which saccades could also be elicited at stimulation thresholds exceeding $50 \mu \mathrm{A}$ ); and (3) adjoining territories of the dorsomedial frontal cortex and of the periarcuate cortex.

Characteristic properties of corticostriatal projections from the $F E F$ and from cortex in and adjacent to $S E F$

Injections both in the FEF and in the medial cortex labeled corticostriatal fibers in a considerable part of the caudate nucleus (Fig. 1), but the fiber projections traced to the striatum from the SEF and adjacent cortex were larger than the projection traced from the FEF, even for medial injection sites smaller than the corresponding FEF injection sites. Injections in SEF and adjacent cortex labeled a strongly bilateral projection to the caudate nucleus and to localized, mainly adjoining, parts of the putamen. The projection field extended from approximately the level of the anterior pole of the putamen ( A24 in the cynomolgus macaque; Szabo and Cowan, 1984) to the level of the posterior body of the caudate nucleus $(\sim \mathrm{A} 9)$. By contrast, the corticostriatal projection traced from the FEF began at about the anteroposterior level of the anterior commissure ( A19). The FEF projection ficlds were restrictcd to the caudate nucleus, striatal cell bridges, and a discrete dorsomedial zone in the putamen, and invariably were much stronger on the ipsilateral than on the contralateral side. Contralateral labeling was present only in regions of the caudate nucleus corresponding to those most heavily labeled on the side ipsilateral to the FEF injection. The parasagittal section illustrated in Figure 1, taken through the medial caudate nucleus, illustrates the full anteroposterior length of a typical FEF projection field. The SEF projection field illustrated, although much larger, actually underrepresents the projection because at more caudal levels, the SEF projection was centered quite laterally in the caudate nucleus.

In all cases, the corticostriatal projections were broken up into densely labeled focal zones less than a millimeter in diameter. These appeared in transverse as well as in sagittal sections as patches of tracer labeling in a surrounding field of much weaker labeling. Serial-section reconstructions of thc distributions of individual tracers were not possible, because we stained se- 

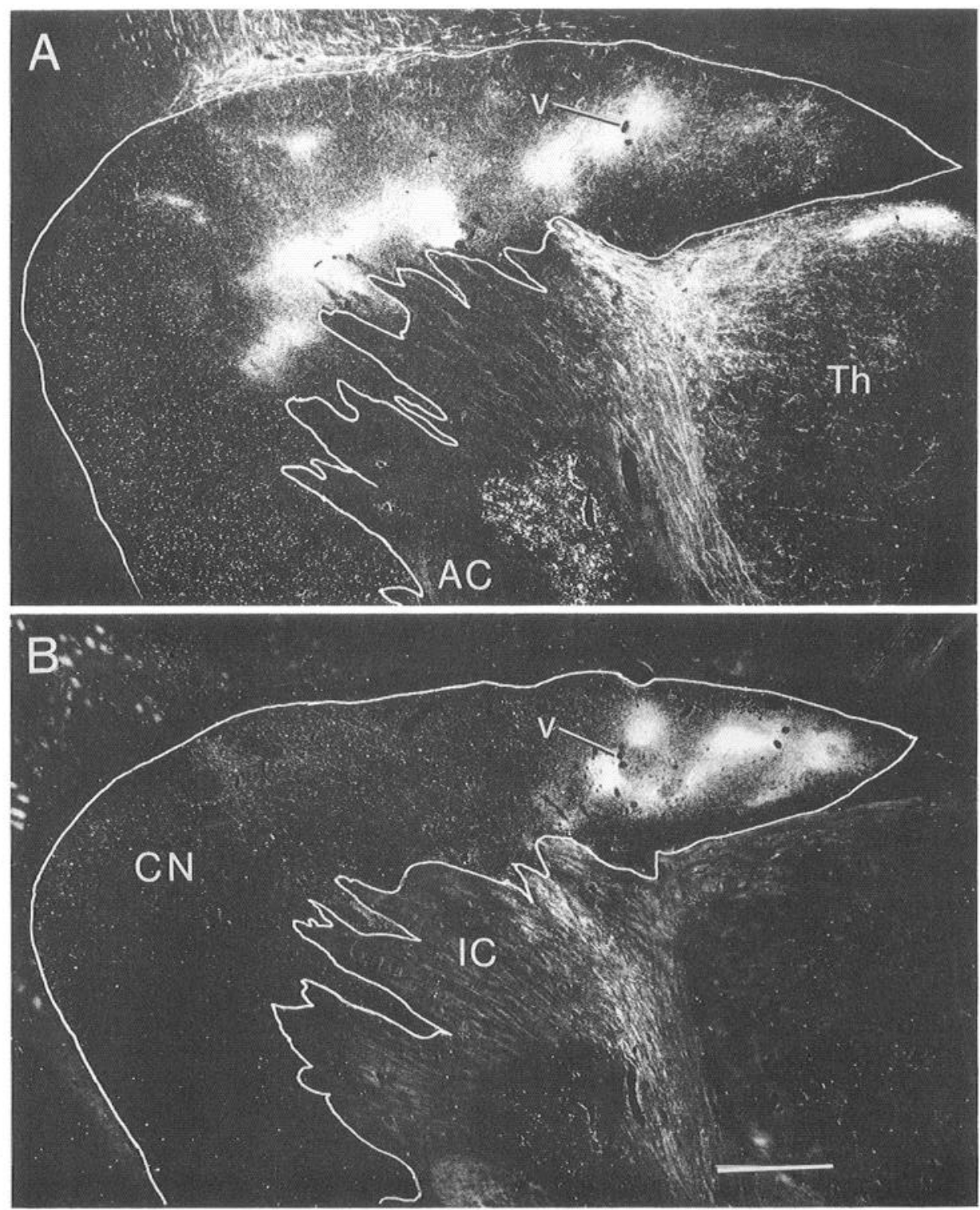

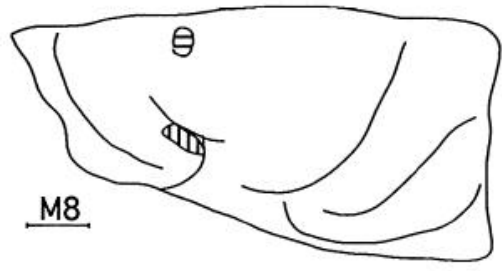

Figure 1. Dark-field photographs illustrating fiber projections traced to the striatum in case M8 from the SEF $(A)$ and the FEF $(B)$ in serially adjacent sagittal sections approximately $3.5 \mathrm{~mm}$ lateral to the midline. $v$ indicates corresponding blood vessels in the two sections. Locations of the two injection sites are shown on the drawing of the hemisphere (SEF site indicated by horizontal hatching; FEF deposit, by vertical hatching). $A$ shows the extensive anteroposterior distribution of the corticostriatal projection traced from a single ${ }^{35} \mathrm{~S}$-methionine injection site centered slightly medial to the center of the SEF as determined by microstimulation. $B$ illustrates the sharply bordered clusters of fibers labeled from the WGA-HRP injection site in the FEF. $A C$, anterior commissure: $C N$, caudate nucleus: $I C$, internal capsule; $T h$, thalamus. Scale bar on photo, $2 \mathrm{~mm}$; on drawing, $5 \mathrm{~mm}$. quential sections for the two tracers and for enkephalin to permit accurate three-way comparisons. Nevertheless, the broken series suggested that many of the input zones that appeared as patches in single sections eventually joined together to form complex three-dimensional aggregates.

\section{Overlapping corticostriatal projection fields are labeled from physiologically guided tracer injections in the SEF and the FEF}

In case M1 (Figs. $2 A, 3,4$ ), we made more than 60 penetrations in order to map out the two cortical eye fields. Microstimulation of cortex at the genu of the arcuate sulcus clearly defined a discrete FEF from which only contraversive saccades could be elicited with currents under $50 \mu \mathrm{A}$. The dorsomedial eye field identified as SEF was clearly delimited by unresponsive cortex and, especially caudally and medially, by cortex in which arm and neck movements could be elicited at low threshold without concomitant eye movements (Fig. 3A). This oculomotor field was centered approximately $5 \mathrm{~mm}$ lateral to the medial edge of the hemisphere and was slightly anterior to the FEF. A single injection of ${ }^{35} \mathrm{~S}$-methionine was made in the SEF, and two closely spaced deposits of WGA-HRP were made into the FEF (Table 1). Both injection sites (SEF, $4 \mathrm{~mm}$ diameter; FEF, $3 \mathrm{~mm}$ diameter) were continuously labeled and spanned all cortical layers (Fig. $3 B$ ). Dense anterograde labeling from the SEF injection site was present bilaterally in the anterior bank of the arcuate sulcus, including the FEF injection site on the ipsilateral side and the corresponding region of arcuate cortex in the contralateral hemisphere (see Figs. $4 A, 9 A$ ).

The corticostriatal projections labeled in this case systematically overlapped one another. As illustrated in Figures $2 A$ and $3 C$, almost every one of the FEF input patches seen in individual sections fell within the bounds of a zone innervated by the SEF. However, the FEF and SEF projections were by no means identical. The FEF input patches were smaller than the SEF patches, and the center of gravity of the FEF projection zone in the caudate nucleus was shifted slightly medially with respect to that of the SEF. Thus, there was often a small patch of FEFderived label medial to the zone of overlap. In keeping with the patterns of corticostriatal projection observed in other cases of 


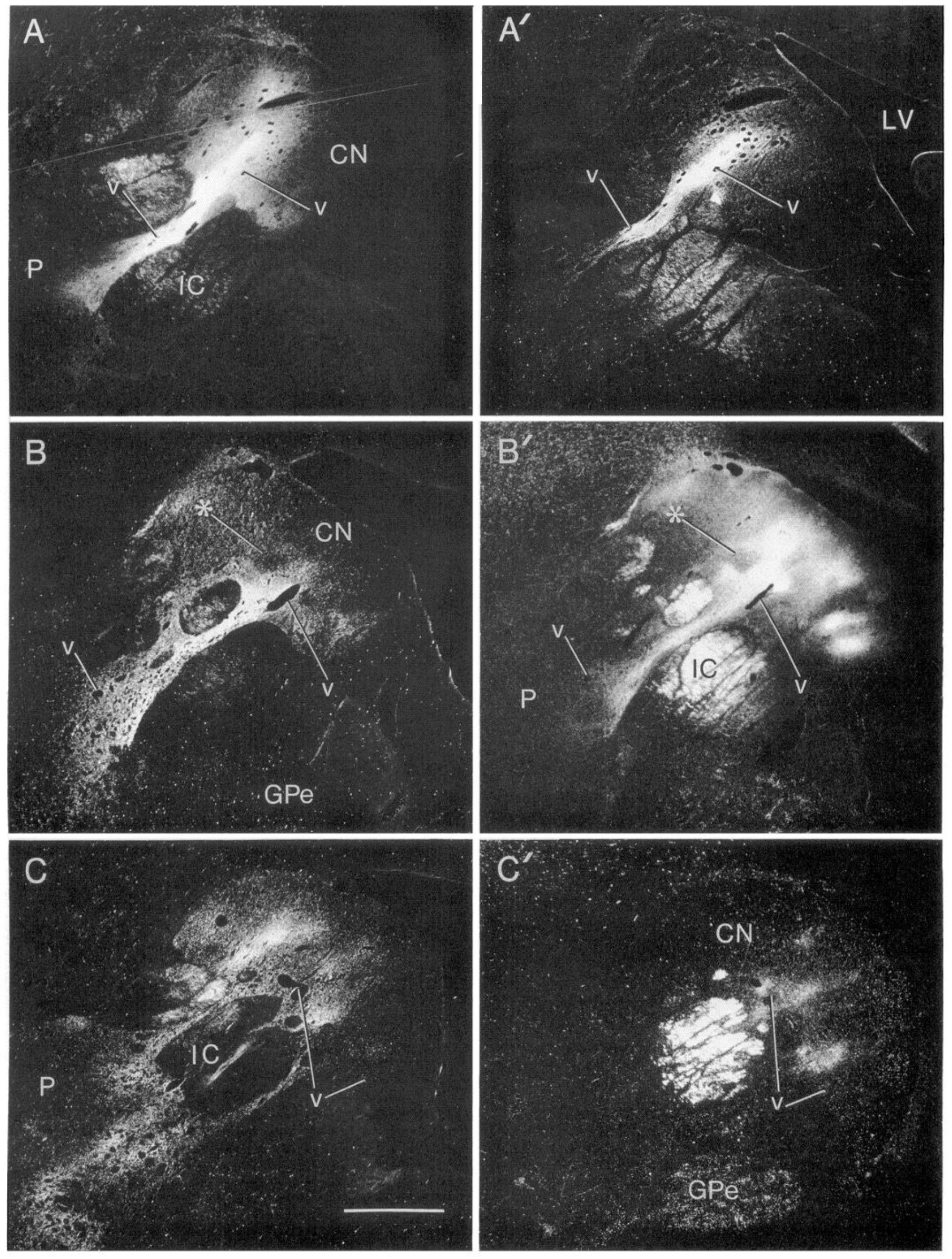


SEF and FEF injections, the SEF projection labeled had a larger anteroposterior field of innervation, and it was strongly bilateral. The smaller FEF injection labeled a projection that was almost entirely confined to the ipsilateral striatum and that extended as far caudally as the SEF projection, but that began 4-5 mm posterior to the rostral appearance of the SEF projection field. The FEF injection labeled a few closely spaced patches in cross sections throughout the body of the caudate nucleus, and was restricted in the putamen to a dorsomedial region, except at the posterior end, where a pattern of strong crisp patches appeared throughout the putamen's dorsoventral length. Nearly all of these FEF input patches overlapped with SEF input zones, but the larger extent of the labeled SEF projection left large parts of that projection unmatched.

The input patches labeled by the SEF injection site varied in size from anterior to posterior. Anteriorly ( $\sim$ A23-A18 in this rhesus macaque; Snider and Lee, 1961), they were very small $(200-300 \mu \mathrm{m})$ both in the caudate nucleus and in the putamen. Farther posteriorly, in the caudate nucleus, cell bridges, and dorsal putamen, the patches seemed at once to coalesce and to become more diffuse, so that the projection field appeared as an almost confluent set of heavily labeled patches running in a single diagonal band through the middle of the striatum. The smaller patches in the middle and ventral putamen persisted only as far caudally as $\sim \mathrm{A} 16$, the level at which the anterior commissure crosses the midline, and then the projection became limited to one patch in the ventrolateral caudate nucleus and one patch in the dorsomedial putamen. This pattern persisted into posterior levels of the putamen, where once again many discrete patches appeared. The SEF projection to the caudate nucleus faded caudally and ended in the posterior body of the caudate nucleus.

The fiber projections from the two eye fields to the thalamus and the superior colliculus were also charted. In the ipsilateral thalamus, the SEF projection field almost completely included the FEF projection field (Fig. $4 B$ ). Zones of overlap were most obvious in the mediodorsal nucleus and in nucleus $\mathrm{X}$. In the ipsilateral superior colliculus, however, the SEF projection was much weaker and was, unlike the FEF input, accompanied by a faint contralateral projection. The zone of SEF projection was shifted medially with respect to that of the FEF so that the two only partially overlapped (Fig. $4 B$ ).

\section{Adjacent corticostriatal projection fields are labeled from the pre-SMA and the FEF}

In case M2 (Fig. 5), we placed a deposit of ${ }^{35} \mathrm{~S}$-methionine medial to the eye movement territory identified as the SEF, and mapped (Fig. 5A) and injected an equal amount of WGA-HRP into the low-threshold arcuate FEF (Table 1). For this monkey, higher stimulation currents were needed to elicit movements from the dorsomedial cortex than for case M1, and the mapping was not as extensive as that for case M1. Nevertheless, we did observe a caudal-to-rostral progression in which arm movements followed by ear and eye movements were elicited by microstimulation. The tracer was injected medial to the eye movement territory, along the medial wall of the hemisphere in the superior frontal gyrus (Fig. 5B). This cortex appears to correspond to a rostral region of the supplementary motor cortex (the medial part of area $6 \mathrm{a} \beta$ of Vogt and Vogt, 1919, or area F6 of Luppino et al., 1991), which does not share somatotopy with the more caudal SMA. The injection site will be referred to provisionally as being centered in the pre-SMA (Tanji et al., 1991; see Discussion).

This pre-SMA injection site $\left({ }^{35} \mathrm{~S}\right.$-methionine) confluently labeled cortex extending 3-4 mm along the shoulder and medial bank of the superior frontal gyrus, and included all cortical layers. The WGA-HRP injection in the FEF was centered in the rostral lip of the arcuate sulcus, spanned 5-6 $\mathrm{mm}$ along the anterior bank, and spread rostrally approximately $3-4 \mathrm{~mm}$ from the sulcus as well as into the underlying white matter. The preSMA injection was centered 1-2 $\mathrm{mm}$ anteriorly to the FEF injection site center. Anterograde autoradiographic labeling from the pre-SMA injection appeared in the postarcuate cortex and along the dorsal and ventral limbs of the arcuate sulcus, but very little labeling was detectable in the prearcuate cortex (see Fig. 9D). Thus, the two cortical sites injected were not transcortically connected, at least in this direction.

In the striatum, there was very little overlap of the corticostriatal projections traced from these FEF and pre-SMA injections. The projection from the FEF (Fig. $5 C$ ) was still very similar to that of the previous case, despite the larger size of the FEF deposit. The pre-SMA projection to the rostral striatum appeared as tiny patches in the putamen and the ventrolateral caudate nucleus (much like the SEF projection field). However, by the level of the crossing of the anterior commissure ( A $\sim 18)$, the clusters of labeled fibers in the putamen became very large and diffuse and the putamen became the main target for the projection along with the lateral caudate nucleus. Thus, the preSMA injection, centered medial to the field from which eye movements were evoked, labeled much more of the putamen than the SEF injection site in the convexity cortex of case M1. Farther posteriorly, the fibers labeled from both injection sites terminated in patches in the caudate nucleus and adjoining dorsomedial putamen. There was a striking tendency for the two sets of patches to lie adjacent to one another where both appeared at the same level.

Tissue was not available for mapping projections to the posterior striatum, the thalamus, and the superior colliculus.

Figure 2. Comparisons of the corticostriatal projections of the SEF/SMA cortex (left) and FEF/arcuate cortex (right) labeled in pairs of serially adjacent transverse sections through the striatum of cases $\mathrm{M} 1(A, A), \mathrm{M} 5(B, B)$, and $\mathrm{M} 3(C, C)$. All sections were photographed under dark-field illumination. $A$ and $A^{\prime}$, Sections at approximately A14 (Macaca mulatta), showing that the WGA-HRP-labeled FEF projection field $(A)$ is almost completely contained within the SEF projection field ( $A$, labeled with ${ }^{3} S$-methionine). The microstimulation map for this case is shown in Figure 3. $B$ and $B^{\prime}$, Sections at approximately A17.5 showing overlap of projections from the SEF, labeled with WGA-HRP $(B)$, and projections from the cortex of the dorsal bank of the arcuate sulcus and the genual arcuate cortex (FEF+; the microstimulation map for this case is shown in Fig. 7), labeled with ${ }^{35} \mathrm{~S}$-methionine $(B)$. The projection from the SEF is almost completely contained within the projection field of the arcuate cortex $(B)$. Note the similarity between the arcuate projection field in this case $(B)$ and the SEF projection field in case M1, shown in $A$. $C$ and $C^{\prime}$, Interdigitation rather than overlap of corticostriatal projections traced from the pre-SMA cortex, labeled with WGA-HRP $(C)$, and from the FEF, labeled with ${ }^{35} \mathrm{~S}$-methionine $(C)$. The sections are at approximately A18. The microstimulation map for this case is shown in Figure 6. $C N$, caudate nucleus; $G P e$, globus pallidus external segment; $I C$, internal capsule; $L V$, lateral ventricle; $P$, putamen; $v$, blood vessel. Scale bar, 2 mm. 

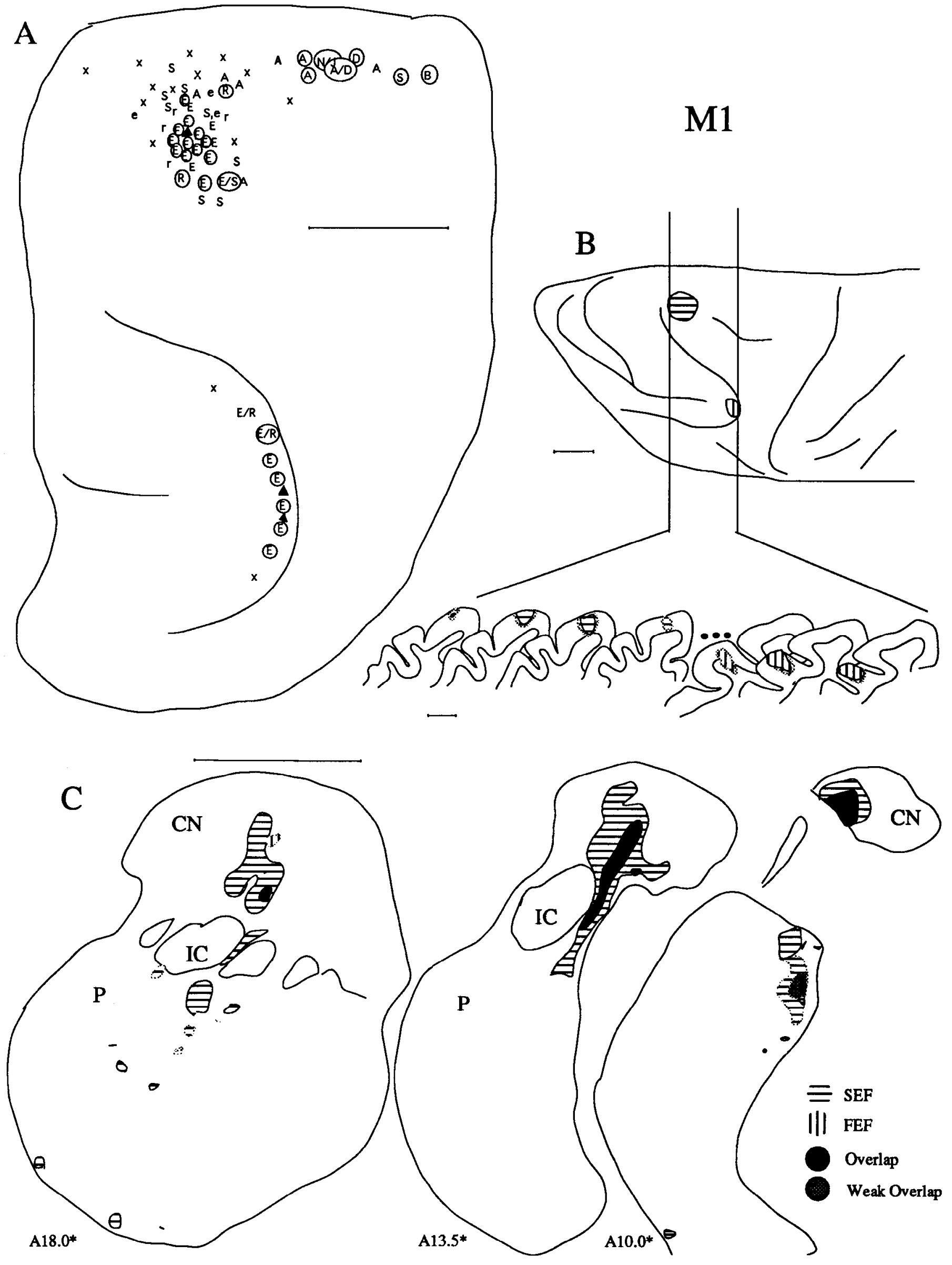

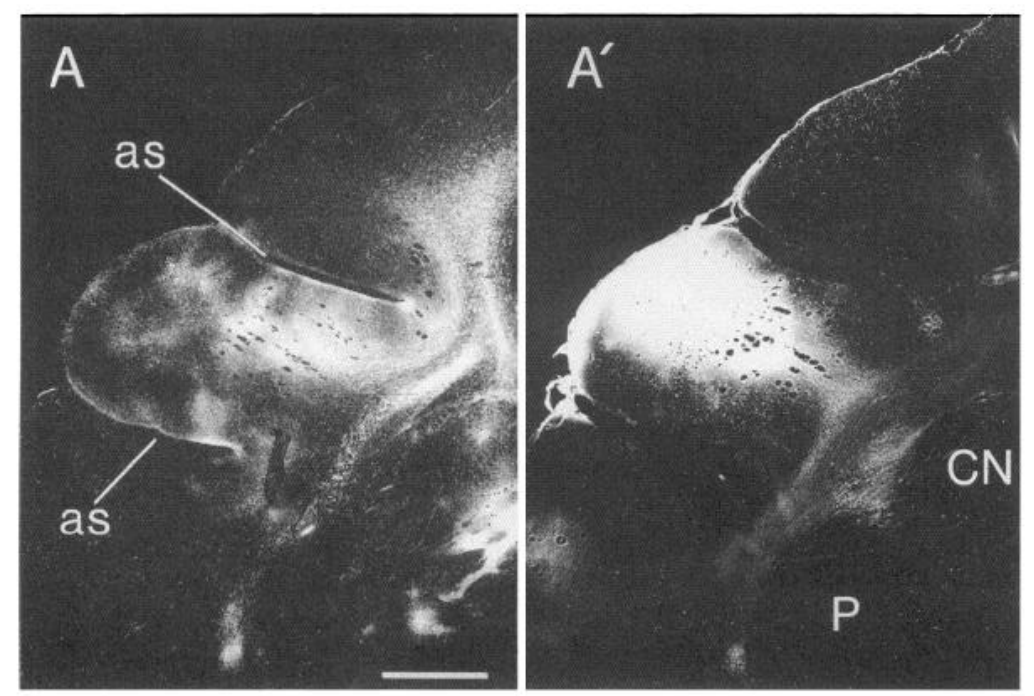

Figure 4. Monkey M1. A, Photomicrographs illustrating the projection of ${ }^{35} \mathrm{~S}$-methionine-labeled fibers from the SEF (left) to the FEF injection site (WGA-HRP, right). $C N$, caudate nucleus; $P$, putamen; as, arcuate sulcus. $B$, Schematic drawings of inputs to the thalamus and superior colliculus from the SEF and the FEF. Symbols are the same as those in Figure $3 C$. $M D$, mediodorsal nucleus; $V L$, ventrolateral nucleus; $S C$, superior colliculus, Teg, tegmentum; $X$, nucleus X. Asterisks after AP coordinates indicate values for Macaca mulatta. Scale bars: $A, 3 \mathrm{~mm}$; $B, 5 \mathrm{~mm}$.
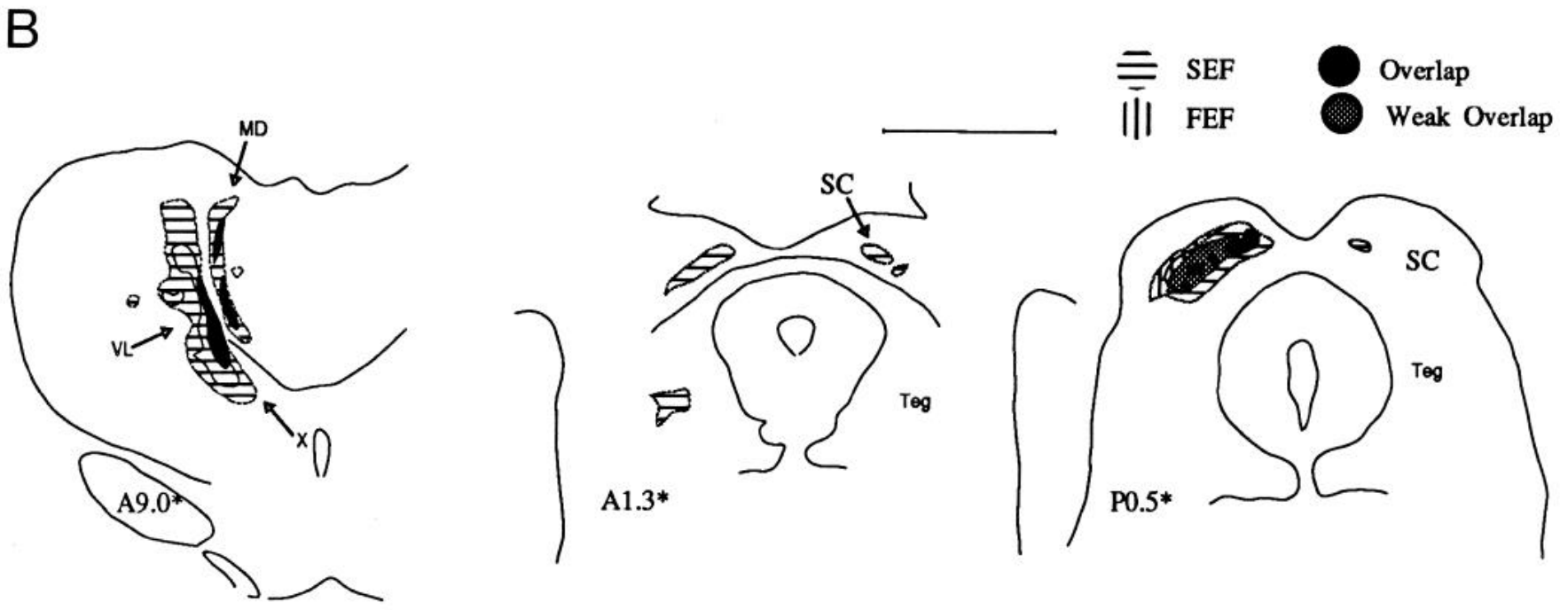

Nonconvergent corticostriatal projections are labeled by tracer injections in rostral pre-SMA eye movement cortex and the FEF

In an attempt to repeat the paired convexity SEF/FEF injections, we once again mapped out and injected the medial and arcuate eye movement territories in case M3, injecting WGA-HRP into the medial cortex and ${ }^{35} \mathrm{~S}$-methionine into the arcuate cortex (Table 1). Unexpectedly, we found practically no overlap of the labeled projection fields in the striatum (Fig. 6). However, a hallmark of the SEF is its cortical interconnectivity with the $\mathrm{FEF}$, and in this case, there was no labeled fiber projection from the FEF injection site detectable at the site of injection in the dorsomedial cortex. Instead, anterograde label traced from the FEF deposit appeared in dorsomedial cortex several millimeters posterior to the injection site, at about the same transverse level as the FEF. Both anterograde and retrograde labeling from the medial injection site were present in the periarcuate cortex, but the label was in radial zones within the posterior bank of the arcuate sulcus and at the fundus of the sulcus, and did not appear in the anterior bank and lip of the sulcus, where the FEF injection site was located (see Fig. 9E). We will use the term "preSMA eye movement cortex" to refer to the cortical zone injected because of its anterior location relative to the FEF and to FEFinnervated medial cortex.

The corticostriatal projection traced from this eye movement

Figure 3. Monkey M1. A, Microstimulation map of frontal cortex, showing sites at which stimulation elicited movements of arm $(A)$, body $(B)$, digit $(D)$, eye $(E)$, hand $(H)$, jaw $(J)$, neck $(N)$, ear $(R)$, shoulder $(S)$, and sites at which no response was evoked $(X)$. Thresholds are indicated by the use of circled capitals for currents $<50 \mu \mathrm{A}$ and uncircled capitals for currents of 50-100 $\mu \mathrm{A}$. Lowercase letters indicate that threshold at the site was not defined. Solid triangles mark injection sites. B. Schematic drawings of the dorsal view of the hemisphere and of cross sections through the SEF injection site ${ }^{35}$ S-methionine, horizontal hatching) and the FEF injection site (WGA-HRP, vertical hatching) (see also Fig. 4). Less intensely labeled marginal zones of the injection sites are indicated by dotted lines. Cross sections are approximately $1 \mathrm{~mm}$ apart except where separated by - . C , Schematic drawings of cross sections through the striatum $(C N$, caudate nucleus; $I C$, internal capsule; $P$, putamen) ipsilateral to the injection sites. Labeled projection fields are indicated by the same symbols used to code the injection sites in $B$. Dotted outlines enclose regions that were weakly labeled compared to the rest of the projection field. Indicated zones of weak overlap are regions of coincident projections from the paired cortical injections in which one or both projection fields was weakly labeled. Asterisks after AP coordinates indicate values for Macaca mulatta (Snider and Lee, 1961). Scale bars, $5 \mathrm{~mm}$. 
cortex appeared very far anteriorly in the caudate nucleus, and labeling was prominent on the contralateral as well as on the ipsilateral side. The projection field included more of the putamen than did the SEF projection in case M1, but less than did the pre-SMA projection in case $M 2$. It began to fade at about the level where the striatum is completely split by the fibers of the internal capsule ( A 15 ), somewhat anterior to the level at which the SEF projection in case M1 dwindled. The FEF projection field had an anteroposterior distribution similar to that seen in case M1.

In the striatum (Fig. $6 C$ ), although the FEF input patches were often next to the pre-SMA input patches, and occasionally interdigitated with them, the two sets of patches rarely overlapped. The only convergence between them was in the striatal cell bridges splitting the internal capsule, and the amount of convergence was small.

Thus, although we are confident that we injected cortical territory from which we could elicit eye movements, both medially and laterally, there were neither interconnections between the two cortical sites injected nor (with rare exceptions) converging corticostriatal projections from them. There was no evidence for convergence of the outputs of these two cortical fields within the thalamus or superior colliculus, either (data not shown). In the thalamus, most of the labeled FEF fibers were medial to the labeled pre-SMA fibers. We could find no transport of WGAHRP to the superior colliculus from the pre-SMA eye movement cortex.

\section{Overlapping corticostriatal projections are labeled from the SEF and the dorsal arcuate cortex}

The FEF injections in the cases just described were aimed at the cortex of the arcuate genu, which has very low microstimulation thresholds for evoking saccades (Bruce and Goldberg, 1985). However, eye movements also can be evoked from cortex adjacent to this low-threshold area (Mitz and Godschalk, 1989), and it has been shown that prearcuate cortex along the dorsal limb of the arcuate sulcus, the "large eye movement" territory (Robinson and Fuchs, 1969), projects more anteriorly in the striatum than does the low-threshold FEF (Stanton et al., 1988). Because we had found in case Ml that the projection to the striatum from the SEF reached more anteriorly than that of the low-threshold FEF, we wondered whether there would be overlap of this more anterior part of the SEF projection field with corticostriatal inputs from the dorsal limb of the arcuate sulcus. We first tested, and confirmed, the arcuate dorsal limb topography by making paired tracer injections in the arcuate eye field of case M4, placing WGA-HRP at the genu of the arcuate sulcus and ${ }^{35} \mathrm{~S}$-methionine in the cortex of the dorsal limb of the sulcus (data not shown). Consistent with observations in single-tracer studies (Stanton et al., 1988), we found that the dorsal limb cortex projects to a larger, more anteriorly placed and more dorsal projection field in the caudate nucleus than does the genual cortex.

Therefore, in M5, we paired a small SEF injection (WGA$\mathrm{HRP}, \sim 3 \mathrm{~mm}$ diameter) with a much larger injection ${ }^{35} \mathrm{~S}$-methionine, $\sim 3-8 \mathrm{~mm}$ ) extending along a large part of the dorsal limb of the arcuate sulcus as well as the dorsal part of the genu of the sulcus (Fig. 7). The arcuate injection site encroached slightly into the postarcuate cortex at the genu, and the SEF injection site spread to the upper part of the medial wall of the hemisphere (Fig. 7B).

Transcortical fibers labeled by the FEF injection projected to a wide zone of medial cortex that included the SEF injection site (see Fig. 9B). WGA-HRP was retrogradely transported from the SEF injection site to periarcuate cortex, but the label was concentrated primarily in the anterior and posterior banks of the genu. There was partial corticocortical connectivity of the two injected sites, with genual cortex apparently being the main area of the arcuate cortex that was connected with the SEF.

There was considerable overlap of the two projection fields in both the caudate nucleus and the putamen (Figs. $2 \mathrm{~B}, 7 \mathrm{C}$ ). In the putamen, the overlap was patch for patch, but in the caudate nucleus, the arcuate input zone labeled was shifted medially and dorsally with respect to the labeled SEF input zone.

The dorsal arcuate cortex projected quite strongly throughout the length of the head and body of the caudate nucleus and the heaviest label appeared dorsally and centrally. In the putamen, tiny discretely labeled patches were present in both the most anterior and the most posterior sections (data not shown); but there was very little tracer visible elsewhere in the putamen, except at its dorsomedial edge. In spite of a very strongly labeled ipsilateral corticostriatal projection from this large injection site, there was less label in the contralateral striatum than would have been produced by a comparable medial cortex projection.

The SEF projection field labeled in this case was restricted to parts of the caudate nucleus and putamen that abutted the internal capsule, to the cell bridges within it, and to discrete patches in the very posterior putamen. The SEF labeling became visible a few millimeters farther posterior than in other cases $(\sim \mathrm{A} 20)$, a few millimeters rostral to the crossing of the anterior commissurc. The restrictcd size and pattern of the SEF projection suggest that the injection site did not include the entire SEF. Accordingly, in spite of the considerable overlap of the two projections in the lateral caudate nucleus and medial putamen and in the striatal cell bridges, the amount of overlap between the SEF and the anterior arcuate may be underestimated in this case (compare Fig. $2 A, B$ ).

\footnotetext{
Figure 5. Monkey M2: microstimulation map $(A)$ and schematic drawings of the injection sites $(B)$ and projection fields $(C)$. Conventions are as in Figure 3, except that in $A$, capital letters indicate thresholds of $100-500 \mu \mathrm{A}$ (thresholds were higher for this monkey than for $\mathrm{M} 1$ ), and in $B$, horizontal hatching represents the pre-SMA injection site $\left({ }^{35} \mathrm{~S}-\mathrm{methionine)}\right.$ and vertical lines represent the FEF injection site (WGA-HRP). The microstimulation map $(A)$ and drawing of the left hemisphere $(B)$ were traced from photographs taken during the experiment. Dotted lines represent the border being traced if it was occluded or not present in these photographs. Scale bars, $5 \mathrm{~mm}$.

Figure 6. Monkey M3: microstimulation map $(A)$ and schematic drawings of the injections sites $(B)$ and projection fields $(C)$. Conventions are as in Figure 3, except that in $A$, circled capital letters indicate thresholds of 50-100 $\mu \mathrm{A}$ and capital letters indicate currents of $100-500 \mu \mathrm{A}$, and in $B$, horizontal hatching represents the pre-SMA injection site (WGA-HRP) and vertical hatching indicates the FEF injection site ( $\left.{ }^{35} S-m e t h i o n i n e\right)$. Scale bars, $5 \mathrm{~mm}$.

Figure 7. Monkey M5: microstimulation map $(A)$ and schematic drawings of the injection sites $(B)$ and projection fields $(C)$. Conventions are as in Figure 3, except that in $B$, horizontal hatching indicates the SEF injection (WGA-HRP) and vertical hatching represents the arcuate injection (35-methionine). Scale bars, $5 \mathrm{~mm}$.
} 

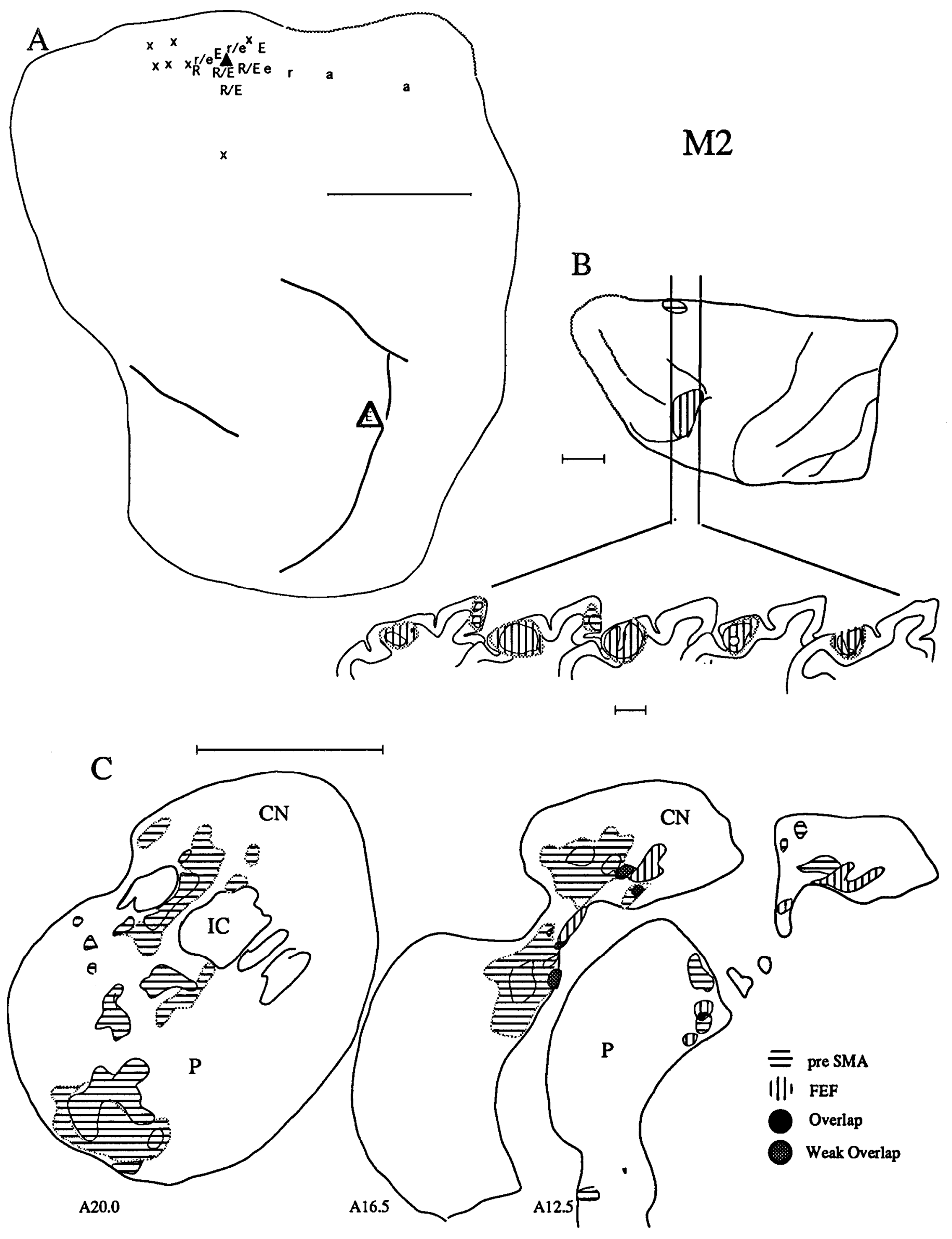

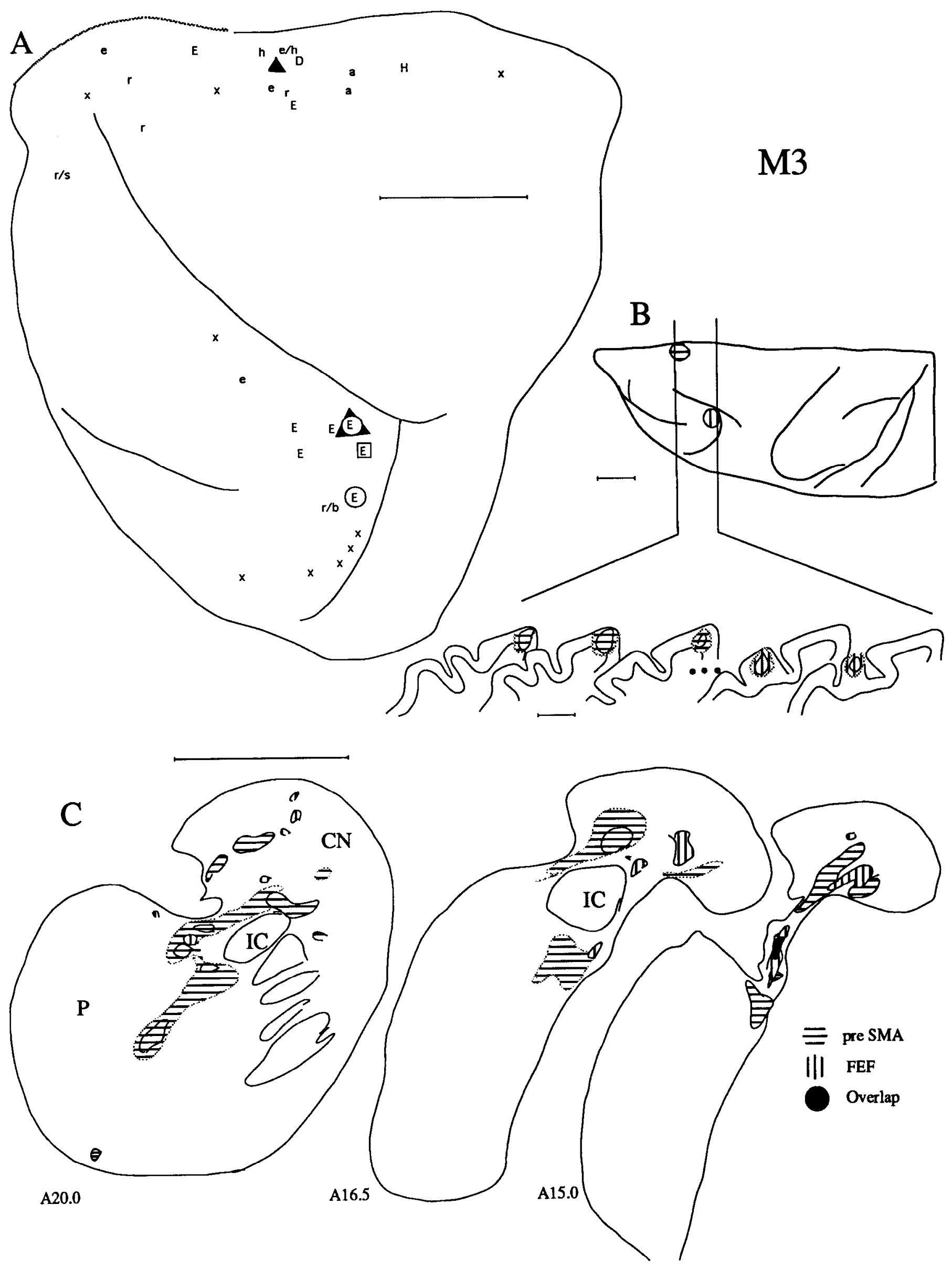

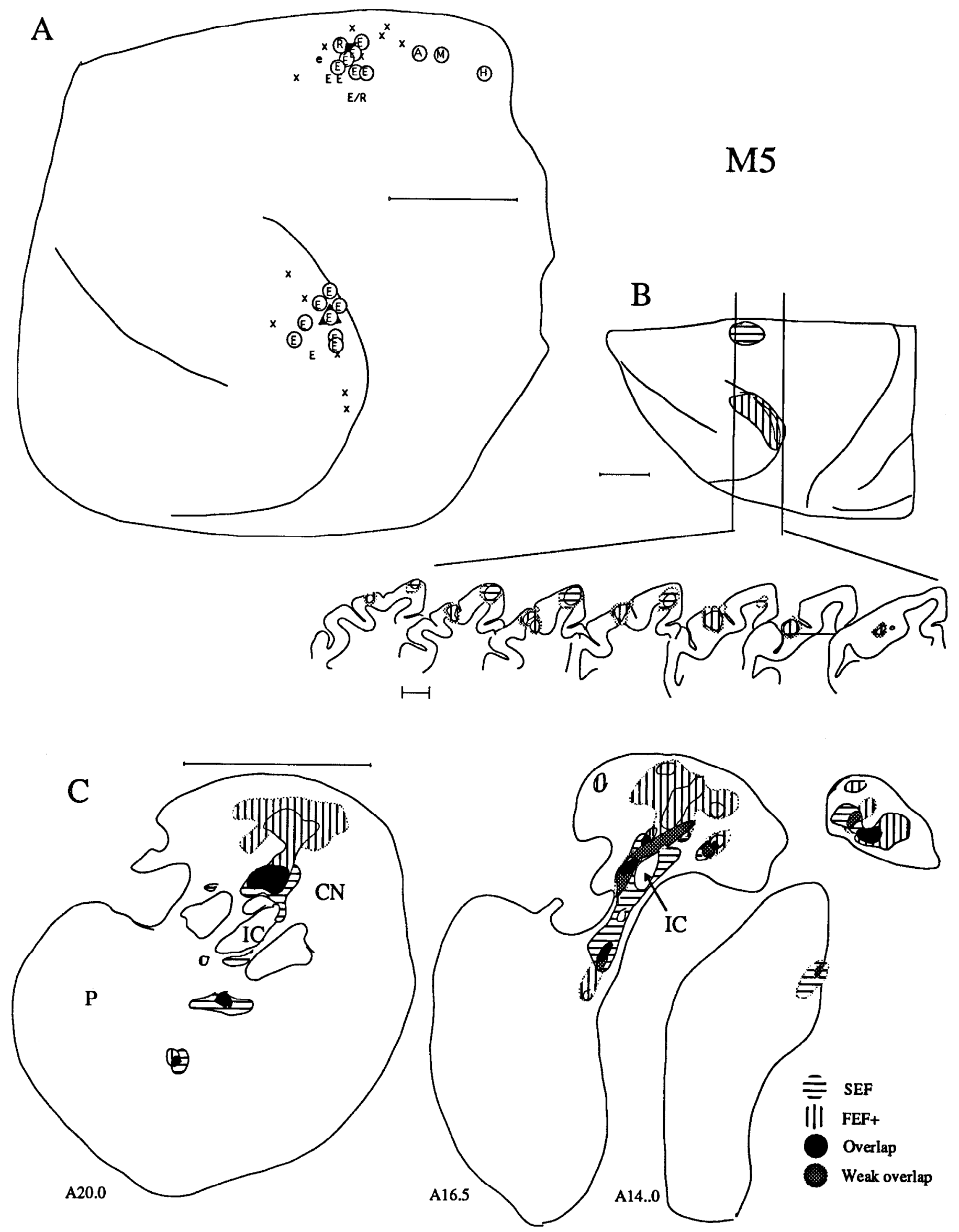

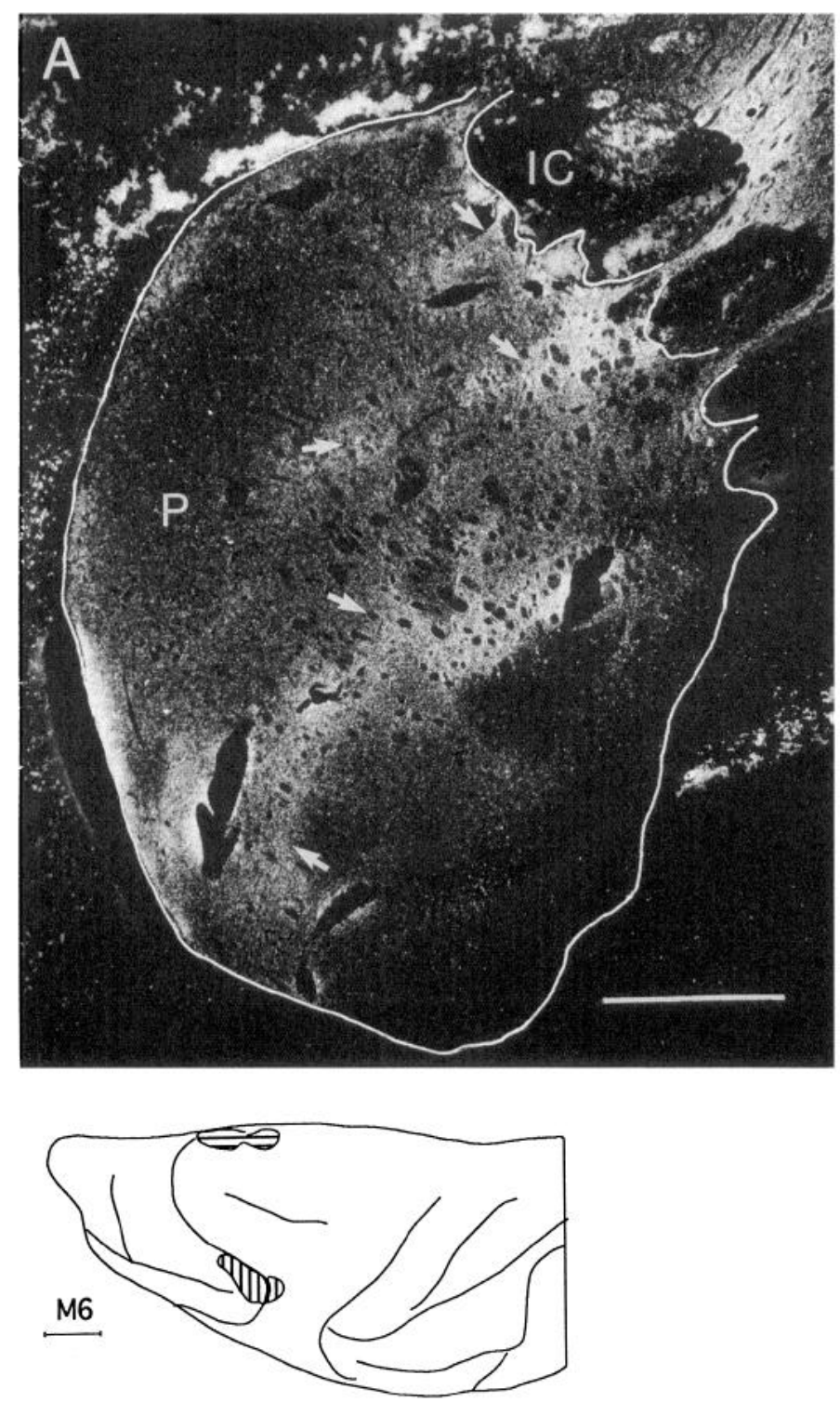

In keeping with the similarities between thalamic and striatal projections observed in other cases, the projection from the SEF and the FEF also showed considerable but incomplete overlap in the thalamus (data not shown). There was no label from the SEF injection in the superior colliculus.

\section{Corticostriatal projections from the medial superior frontal gyrus and the periarcuate cortex suggest their convergence in the putamen}

In order to follow up on our finding of massive labeling of the putamen following injection of the medial face of the superior frontal gyrus in case $\mathrm{M} 2$, and the increase in putamenal labeling we saw from the one FEF injection that included the postarcuate cortex (in case M5), we paired a medial superior frontal gyrus injection with an injection in periarcuate cortex that extended through the fundus of the arcuate sulcus onto the postarcuate convexity cortex (case M6; Fig. 8). We had already noted the presence of strong corticocortical connections between the medial superior frontal gyrus and the postarcuate part of area 6 in case M2 (Fig. 9D). Guided by these results, we injected WGAHRP along an 8-9 mm extent of medial cortex in the vertical

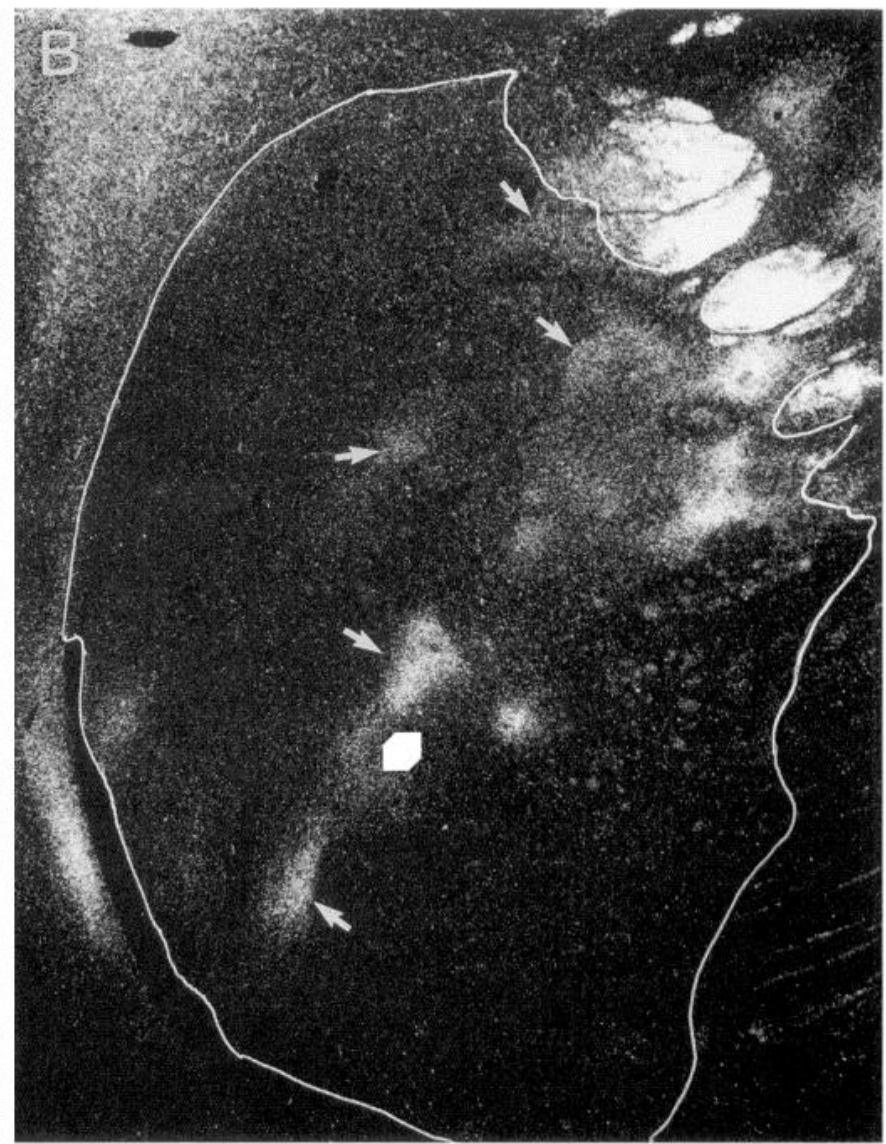

Figure 8. Dark-field photomicrographs of serial transverse sections at approximately A19 illustrating projections to the putamen in monkey M6 traced from the SMA ( $A$, WGA-HRP) and from arcuate cortex ( $B$, ${ }^{35} \mathrm{~S}$-methionine). Injection sites are labeled on the drawing of the dorsal view of the hemisphere (SMA site is marked with horizontal hatching FEF injection site, by vertical hatching). Examples of overlap of labeled patches are indicated by arrows. $I C$, internal capsule; $P$, putamen. Scale bar on photo, $2 \mathrm{~mm}$; on drawing, $5 \mathrm{~mm}$.

wall of the superior frontal gyrus and made a large injection of ${ }^{35} \mathrm{~S}$-methionine into pre- and postarcuate cortex (Table 1). This site presumably corresponded to the SMA and perhaps also to the pre-SMA. The injection site placement was based on cortical topography alone; there were difficulties in maintaining appropriate levels of anesthesia during the experiment, and in fact, we were unable to identify reliably a discrete dorsomedial oculomotor field to which we could directly relate our injection into the medial cortex.

Transcortical autoradiographic labeling from the pre- and postarcuate injection site clearly overlapped with the site injected in the medial wall of the hemisphere (Fig. 9C). In addition, anterograde WGA-HRP labeling from the medial injection site was found along the postarcuate cortex of the genu and lower limb.

Along with a labeled fiber projection to the caudate nucleus that was reminiscent of that seen in other cases, we observed a discretely patchy projection from the large arcuate injection site to the main body of the putamen in this case-a projection not labeled in the other cases with FEF injections, in which the tracer deposit did not reach the arcuate fundus and postarcuate 

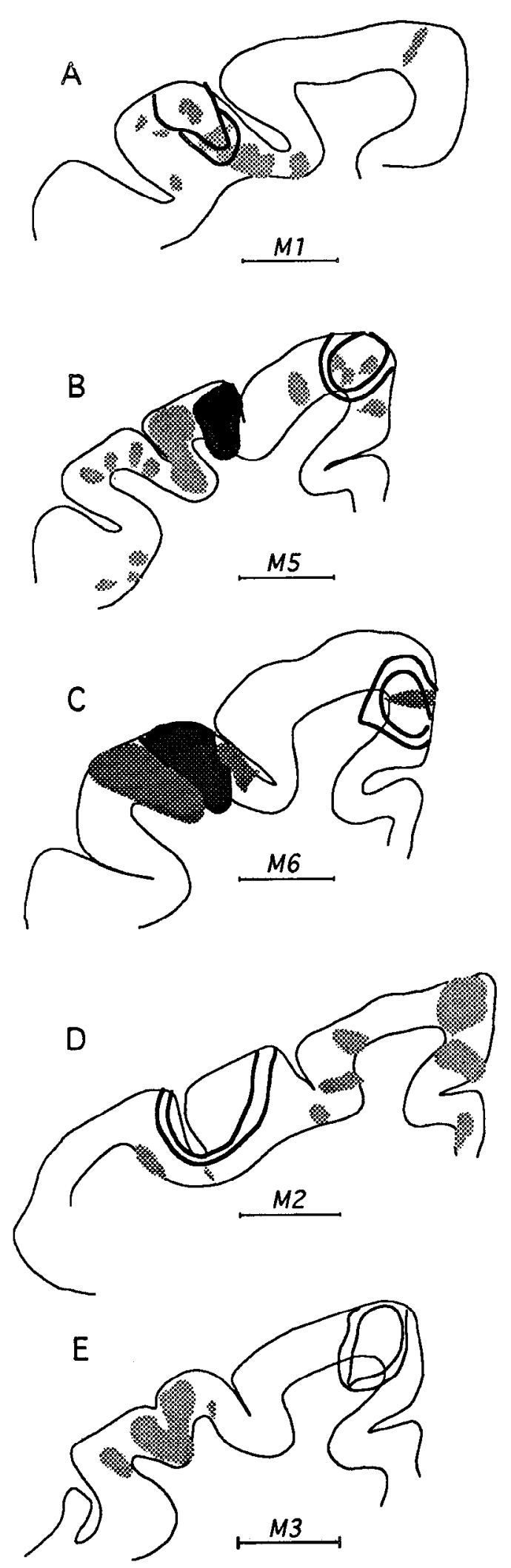
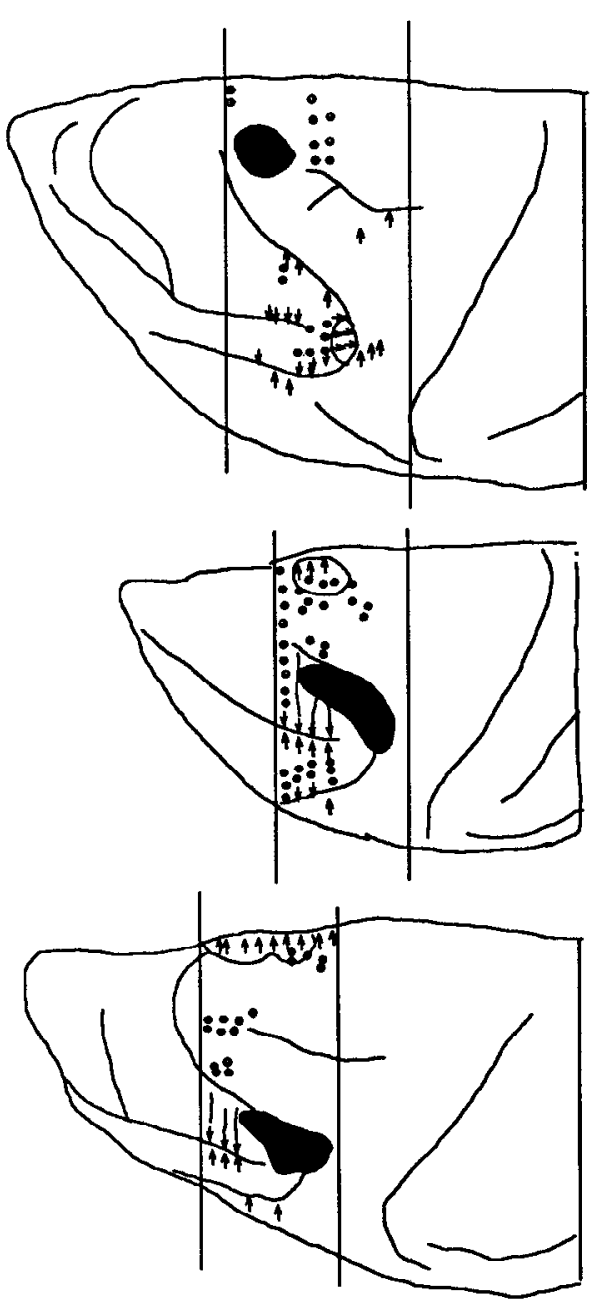

Figure 9. Diagrams summarizing patterns of connectivity between cortical sites injected in five experiments: transverse sections through the WGA-HRP injection sites (injection site and its halo are outlined); projections from the ${ }^{35} \mathrm{~S}$ methionine injection sites are indicated by light shading. Darker shading shows the part of the ${ }^{35} \mathrm{~S}$-methionine injection site visible at the level illustrated. Corresponding dorsal views of the brains are shown on the right. The WGA-HRP injection is outlined. The ${ }^{35}$ S-methionine injection site is indicated in black, and projections traced from it are charted between the vertical lines at approximately $1 \mathrm{~mm}$ intervals. Circles indicate labeling of convexity cortex. Arrows indicate labeled cortex buried within a sulcus. In monkey M1 $(A)$, the SEF projects to cortex at the FEF injection site, and in monkey M5 (B), arcuate cortex projects to cortex at the SEF injection site. $C$ illustrates the connectivity between arcuate cortex and the SMA injection site in monkey M6. No interconnectivity of the injected cortical sites was seen in case $\mathrm{M} 2(D)$, indicating that rostral SMA cortex does not project to the FEF. Nor were corticocortical connections found in monkey M3 $(E)$ between the pre-SMA oculomotor area and the FEF. Scale bars (under case names) indicate $5 \mathrm{~mm}$ and apply to the cross sections only. cortex. The putamenal projection in M6 converged at many points with the more diffusely labeled projection from the medial cortex to the putamen (Fig. 8). This overlap makes it likely that the fundal/post-arcuate cortex and the medial wall cortex send at least partly, and probably highly, convergent projections to the putamen. By contrast, in the caudate nucleus, the patches respectively labeled from the two injection sites were largely nonconvergent. In fact, the pattern of labeling in the caudate 

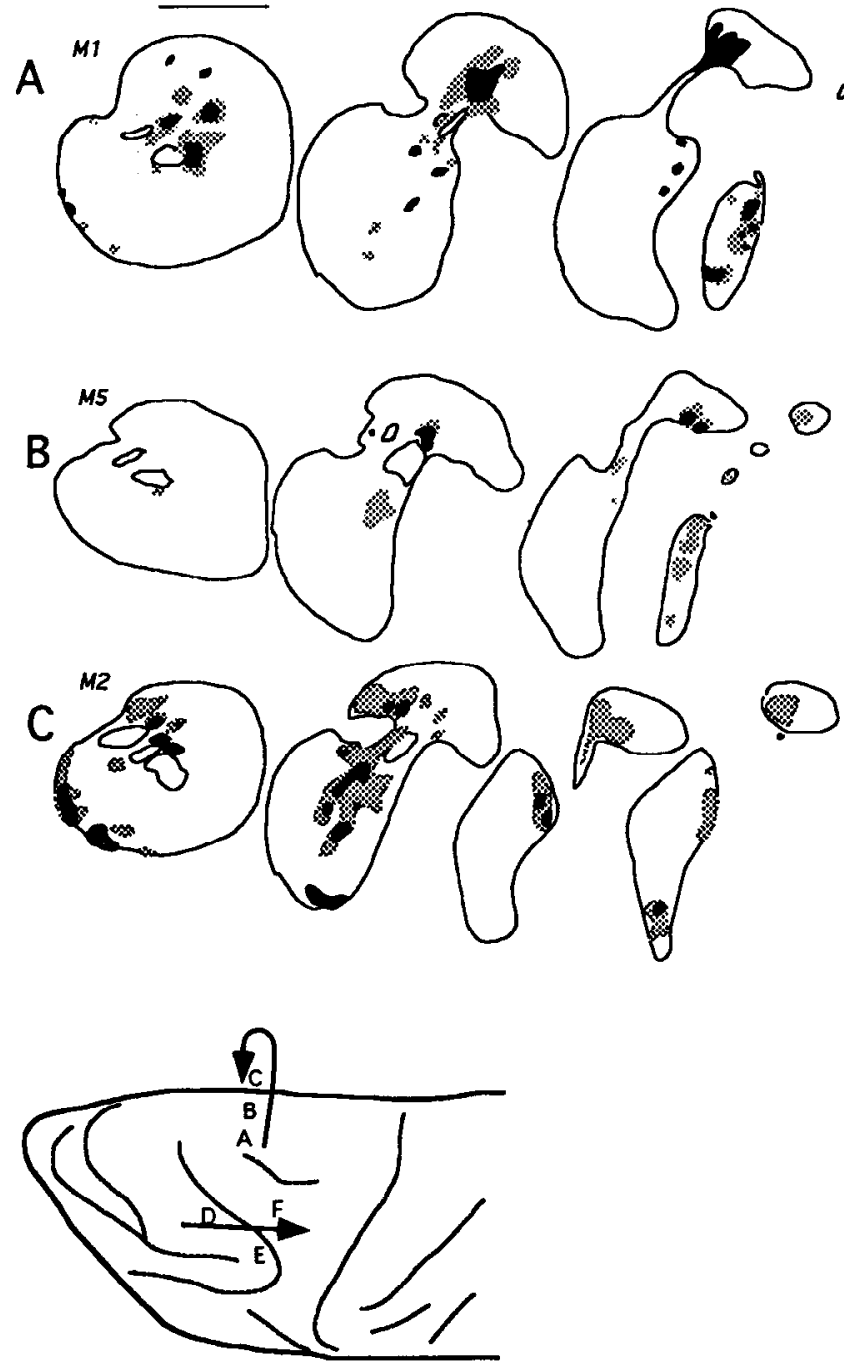

nucleus was quite similar to that of case $\mathrm{M} 2$, in which a large medial wall injection was paired with an injection confined to the prearcuate genual cortex.

The corticostriatal projections from dorsomedial cortex and arcuate cortex follow different topographic ordering

Despite the fact that no simple topographic rule seemed to account for the pattern of dispersed and often far-flung patches of corticostriatal input (see Discussion), we found that cortical topography was predictive of the relative distributions of projections to the striatum labeled from local territorics in and around the FEF and SEF (Fig. 10). In the dorsomedial frontal cortex, we injected laterally placed sites in the dorsal convexity cortex (Figs. $3 B, 7 B$ ) as well as more medial sites, including cortex along the medial bank (Figs. 8, 5B). Comparing the labeled projections resulting from progressively more medial injection sites (Fig. $10 A-C$ ), we saw a corresponding shift of striatal projection fields from one that was centered dorsally in the caudate nucleus (Fig. 10A) to one that was centered ventrally in the putamen (Fig. 10C). There was a similar ventral shift of projection patterns within the striatum for arcuate injection sites
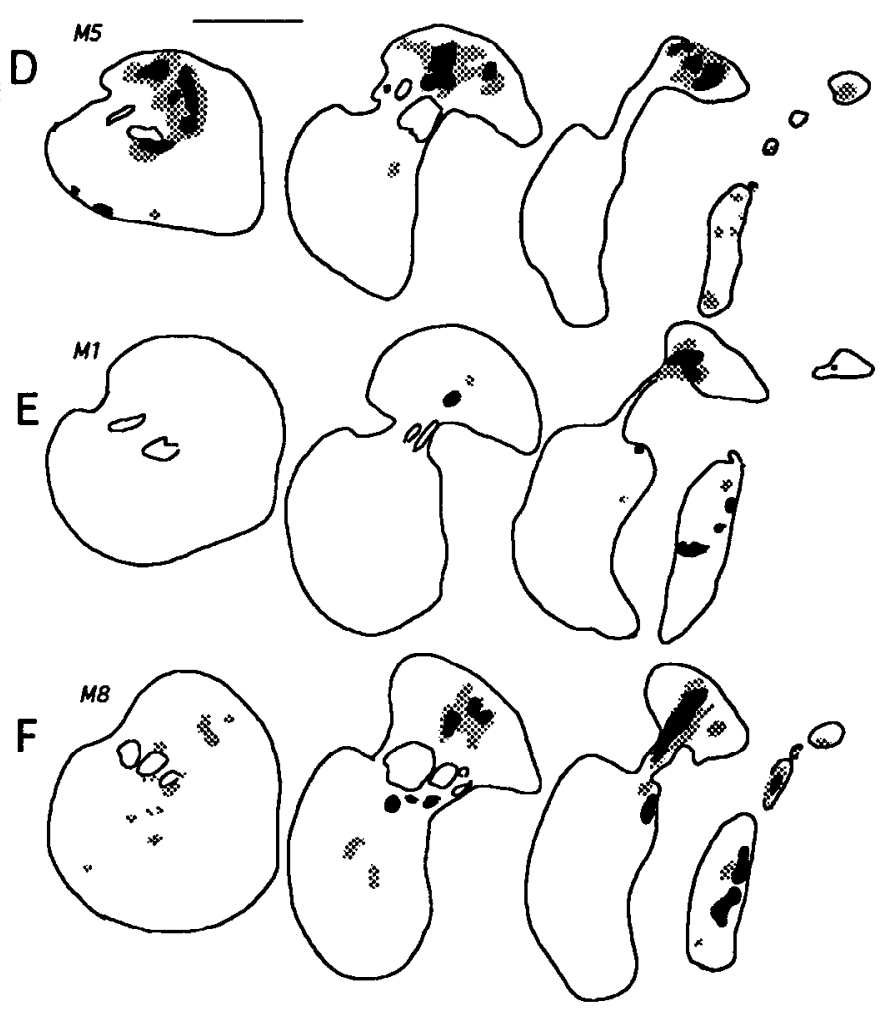

Figure 10. Topographic order of corticostriatal projections from the periarcuate cortex and from the SMA/peri-SMA cortex shown in schematic drawings from six representative cases. Strongly labeled projections are shown in black; lighter shading represents qualitatively more weakly labeled projections. In the SMA region, more lateral cortex projects dorsomedially in the striatum $(A)$ and progressively more medial cortex in the SMA region ( $B$, then $C$ ) projects to striatal districts centered progressively farther ventrolaterally in the striatum. A similar pattern was found for anterior to posterior arcuate cortex $(D-F)$. Scale bars, $5 \mathrm{~mm}$.

placed at successively more posterior locations along the dorsal limb of the arcuate sulcus (Fig. 10D,E).

\section{Corticostriatal projections from oculomotor and premotor areas of the frontal lobe terminate primarily in the extrastriosomal matrix}

In all monkeys, we compared the distribution of the corticostriatal projections labeled by each injection with the locations of striosomes identified in adjacent sections. In every instance, the projection fields were predominantly in the matrix. Heavily labeled input patches sometimes abutted striosomes, but they were never coincident with them. There often were higher background levels of tracer in striosomes located within the labeled striatal districts than the background levels of labeling in the sections, but we never observed heightened input labeling of striosomes relative to input labeling of the nearby matrix. There was a tendency for the FEF labeled projections to avoid striosomes more crisply than those labeled from SEF or from adjoining cortex of the medial wall of the hemisphere (Fig. 11). However, labeling from the largest arcuate cortex injections did not as crisply avoid striosomes (Fig. $2 B$ ). Moreover, even in case $\mathrm{M} 7$, in which we injected $3.5 \mu \mathrm{l}$ of WGA-HRP over a 10 

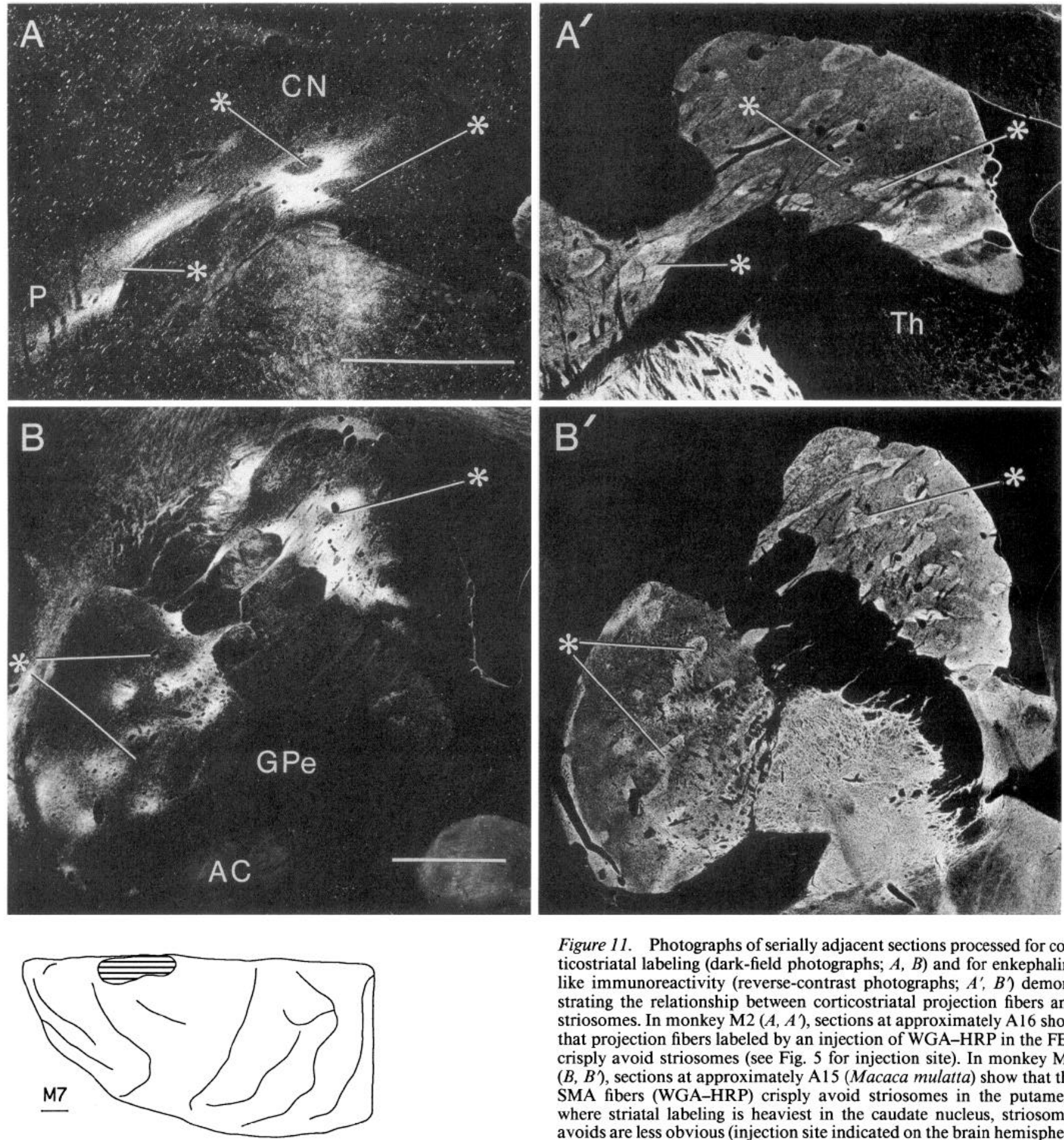

mm length of dorsomedial cortex and produced massive labeling in the striatum, striosomes in the putamen were surprisingly devoid of label, and those in the caudate nucleus were poorly labeled relative to the surrounding matrix (Fig. 11B). We could not determine whether the weak labeling in the striosomes in some projection fields resulted from spread of tracer from the extremely intense labeling of adjoining matrix, or was actually attributable to a bona fide projection to the striosomes. It was clear, however, that matrix labeling predominated throughout the case material.

Figure 11. Photographs of serially adjacent sections processed for corticostriatal labeling (dark-field photographs; $A, B$ ) and for enkephalinlike immunoreactivity (reverse-contrast photographs; $A^{\prime}, B$ ) demonstrating the relationship between corticostriatal projection fibers and striosomes. In monkey $\mathrm{M} 2(A, A)$, sections at approximately $\mathrm{A} 16$ show that projection fibers labeled by an injection of WGA-HRP in the FEF crisply avoid striosomes (see Fig. 5 for injection site). In monkey M7 $(B, B)$, sections at approximately A15 (Macaca mulatta) show that the SMA fibers (WGA-HRP) crisply avoid striosomes in the putamen; where striatal labeling is heaviest in the caudate nucleus, striosomal avoids are less obvious (injection site indicated on the brain hemisphere shown here). Asterisks indicate the locations of corresponding striosomes on the pairs of sections. $A C$, anterior commissure; $C N$, caudate nucleus; $G P e$, globus pallidus external segment; $P$, putamen; $T h$, thalamus. Scale bars, $3 \mathrm{~mm}$.

\section{Discussion}

Our findings demonstrate three striking properties of the corticostriatal projections from the principle oculomotor fields of the primate frontal cortex. First, the FEF and the SEF, although separated from one another by many millimeters and although innervating a dispersed set of patchy zones in the striatum, have 
projections that overlap. often patch for patch, in parts of their striatal termination fields. Second, cortical areas that lie adjacent to the FEF and the SEF project to patches of striatum that tend to lie adjacent to the oculomotor input patches. Third, the corticocortical connectivity of the oculomotor fields and the cortical areas adjoining them is predictive of their corticostriatal connectivity: interconnected cortical areas send projections to the striatum that are at least partly coincident, whereas nearby but unconnected cortical areas send projections to the striatum that are largely nonoverlapping. We conclude that on a macroscopic anatomical level, there is major convergence within the oculomotor circuit of the basal ganglia. Hence, parallel processing is not the exclusive principle of organization of pathways from the forebrain through the basal ganglia. We further show that patterns of termination of corticostriatal fibers are subject to rules of intrinsic striatal organization. Ultimately, therefore, the distributions and degree of convergence of corticostriatal inputs are governed by multiple constraints at more than one level of organization.

\section{Convergence of SEF and FEF projections within the oculomotor sector of the striatum}

We originally chose to focus our study on the FEF and the SEF because these cortical areas are functionally related - and indeed are interconnected cortically - but appear to represent different modes of oculomotor processing. The strict parallelist model of basal ganglia function would predict that these cortical areas, by sending separate inputs to the striatum, set up independent basal ganglia output pathways coding different oculomotor parameters. Our results clearly do not support this prediction. In the cases in which we injected discrete low-threshold, saccade-related SEF and FEF regions, there was systematic overlap of the projections from the two eye fields. If the observed convergence persists at the level of individual neurons within the zones of overlap, this would mean that signals from the two eye fields, only one of which is thought to be eye-position dependent, must combine in the striatum. Even if the convergence were not at the single-neuron level, the fact that fibers from the two eye fields project to the same local patches of striatum makes it highly likely that functional interactions between the two macroscopically convergent systems occur within the striatum.

We were unable to determine the full extent of convergence of FEF and SEF projections to the striatum not only because of limitations inherent in our technique of microstimulation in ketamine-anesthetized monkeys, but also because the definitions of these cortical areas are still undergoing refinement and are sensitive to which methods are used to probe them. On the basis of repeated experimentation, the arcuate eye field has been reduced from one including the entire prearcuate region posterior to the principle sulcus (Ferrier, 1875; Robinson and Fuchs, 1969; reviewed in Goldberg and Seagraves, 1989) to a lowthreshold zone at the junction of cytoarchitectonic areas 8 and 45 , at the genu of the arcuate sulcus along its rostral bank (Bruce and Goldberg, 1985; Stanton et al., 1989). However, saccades with large amplitudes can be elicited in the dorsal prearcuate cortex (Robinson and Fuchs, 1969), and smooth-pursuit eye movements have been elicited by microstimulation at the fundus of the sulcus (MacAvoy et al., 1991). New recording and stimulation studies have also suggested that the originally identified SEF (Gould et al., 1986; Mitz and Wise, 1987; Schlag and Schlag-Rey, 1987; Huerta and Kaas, 1990; Schall, 1991a; in humans, Fox et al., 1985) may be part of a larger region iden- tifiable in the alert monkey as being engaged in the control of saccadic eye movements and/or gaze fixation (Tehovnik and Lee, 1990). It is not yet clear how this larger area overlaps with the map of the body in the SMA (Woolsey et al., 1952; Mitz and Wise, 1987).

With these experimental findings in mind, we prepared cases with arcuate injection sites limited to the low-threshold genual FEF and other cases with larger arcuate injections extending rostrally into the dorsal prearcuate cortex and posteriorly into fundal and postarcuate cortex. With enlargements of the arcuate injection sites, we saw systematic increases in the striatal territory innervated, which included more anterior and dorsal caudate nucleus for the dorsal arcuate injections and more ventral caudate nucleus and putamenal regions for more caudal arcuate injections. To study the SEF, we injected the most discrete saccade-related territory we could identify, but noted that movements of the ear, neck, or even shoulder often were elicited at nearby sites or at the same sites along with saccades. We also injected a very large medial territory in one monkey in which the oculomotor field and associated forelimb movement region had been identified in the alert state (Tehovnik and Lee, 1990; Schall, 1991a). We did not see major differences in the projection mapped out in this animal and those from smaller injections of the medial cortex except that, not surprisingly, there was a much more massive projection labeled from the larger deposit.

Despite the fact that both stimulation and recording studies have demonstrated oculomotor-related properties in larger areas of the frontal lobe than exclusively the low-threshold FEF and the discrete SEF first identified in the macaque by Schlag and Schlag-Rey (Joseph and Barone, 1987; Boch and Goldberg, 1989; Funahashi et al., 1989; Mitz and Godschalk, 1989; Bon and Lucchetti, 1990; Tehovnik and Lee, 1990), we were, in general, unable to find precisely overlapping labeled projections when we paired injections of one discrete eye field with injections from cortex surrounding the other eye field. One case (M5) suggested that the anterior projection to the caudate nucleus from SEF may be matched by projections from the cortex of the dorsal limb of the arcuate sulcus; however, the dorsal arcuate cortex projected to dorsomedial territory in the anterior caudate nucleus, in which we never saw label from an SEF injection. More remarkably, in one other case (M3), we injected an eye field resembling the SEF and found almost no overlap of its projections to the striatum and those from the low-threshold FEF. On the basis of cortical interconnectivity, the medial area could not be confirmed as the SEF, and in fact is more likely to be an eye movement territory rostral to SEF. Rizzolatti and coworkers have also described a second medial eye field in the dorsomedial frontal cortex (Camarda et al., 1991). If this analysis is correct, "oculomotor processing" alone is not a sufficient criterion for directing cortical projections to the SEF/FEF input patches in the striatum.

\section{Functional implications of convergence of oculomotor input to the striatum}

Neurons in the caudate nucleus have saccade-related profiles resembling those of some FEF and SEF neurons (Hikosaka et al., 1989a). The onset of their activity is usually presaccadic, related to intentional rather than to spontaneous saccades, and often shows a preparatory phase. These task-related cells have been found in regions of the caudate nucleus, the striatal cell bridges, and the dorsal putamen that appear comparable to zones of FEF and SEF inputs documented here (compare Fig. 
1 with Hikosaka et al., 1989a, Fig. 6). Units in the caudate nucleus also show fixation-related activity similar to that seen in many forebrain regions including the SEF (Schlag and SchlagRcy, 1987). No studies have yet addressed the question of what coordinate frame the striatal cells encode, but Hikosaka et al. (1989a) did observe some units with activity that was modulated by eye position. One possibility raised by our findings is that FEF saccade-related signals in retinotopic coordinates and SEF saccade-related signals in oculocentric coordinates are combined in the striatum. This hypothesis suggests not a parallel model for the two corresponding oculomotor paths to the striatum, but an integrative model in which striatal neurons form systematic combinatorial computations.

In addition to units with activity that correlates with the sensory and/or motor facets of saccade paradigms, the caudate nucleus also contains cells that seem to fire in expectation of target or reward (Hikosaka et al., 1989b). Hikosaka and coworkers found that these neurons were often located more anteriorly in the caudate nucleus, in regions that may correlate with the anterior projections we observed from the SEF (case M1) and from our large dorsal arcuate injection (case M5). Anticipatory activity of this kind has been found in the dorsolateral prefrontal cortex, but also has been recorded in the SMA (Kurata and Tanji, 1985). The SEF might play a stronger role in modulating the more straightforward saccade execution-related activity of the FEF with behavioral cues.

The doubly inhibitory path from the oculomotor district of the caudate nucleus to the superior colliculus by way of the substantia nigra is thought capable of facilitating orienting saccadic eye and/or head movements to actual or remembered targets (Hikosaka and Wurtz, 1983b; Chevalier and Deniau, 1990). The effects of Parkinson's disease on oculomotor abilities are of some interest in this context. There are not only deficits in saccadic latency, amplitude, and peak velocity [as well as deficits for smooth-pursuit, optokinetic nystagmus, and vestibuloocular reflex (VOR) eye movements], but also an impairment of eye-head coordination for large gaze changes (White et al., 1983, 1988). Though it was once thought that the VOR could completely integrate the head and eye movement systems, it is now known that for large gaze saccades, the VOR is inoperative and that eye-head coordination must be accomplished farther centrally (Tomlinson and Bahra, 1986). The oculomotor striatum could be in a position to participate in this processing by combining cortical information to coordinate orienting movements.

\section{Functional implications of differences between the FEF and the $S E F$ projections to the striatum}

Although we found convergence of FEF and SEF outputs to the striatum (and to the thalamus), in at least three interesting respects the outputs of the FEF and SEF were notably different. First, there was a considerable expanse of the striatum, in the head of the caudate nucleus, in which the SEF input was not matched by FEF input. More anterior parts of the arcuate cortex did project to this more rostral striatal territory. Thus, there are rostrocaudal differences in the inputs to the oculomotor sector of the striatum. Hikosaka et al. (1989a,b) have found subtle differences in the rostrocaudal distributions of unit activity profiles in the caudate nucleus that may relate to the differences in cortical input that we have observed.

Second, taken together, our cases suggest that the direct projection from the SEF to the superior colliculus is much weaker than that from the FEF. The fact that the SEF has a weak direct path may give special functional importance to its indirect cortico-striato-nigro-tectal projection. It could be involved more in setting conditions for release of saccades specificd by other cortical and subcortical areas rather than in directing the eye movements itself.

A third difference between the descending projections from the two eye fields is that the SEF projections to the striatum (and, in part, to the superior colliculus) are bilateral, whereas the FEF projection is predominantly ipsilateral. Given that the task-related neurons in the caudate nucleus are mostly related to contraversive eye movements, the strong contralateral SEF projection may not relate to sensorimotor parameters per se but to other functions of saccadic organization. Humans with cortical lesions involving the SMA but sparing the FEF are reported to have bilateral impairments in performing remembered sequences of saccades, while maintaining normal reflexive and memoryguided saccades (Gaymard et al., 1990). By contrast, deficits occurring after lesions of the FEF are reported to be unilateral (affecting the visual field contralateral to the cortical lcsion) (Guitton et al., 1985). In monkeys, lesions of the SMA also disrupt bilateral (bimanual) tasks (Brinkman, 1984), and neurons in the primate SMA that code for arm movement sequences have been reported (Mushiake et al., 1990). The SMA, including its rostral oculomotor representation, the SEF, may be specialized for such sequential ordering of bilateral movements, the metrics of which are programmed elsewhere. In contrast, the FEF appears to code for the next contraversive saccade (Goldberg and Bruce, 1990). These differences in function of the two cortical areas may be reflected in the degree of bilaterality of their striatal projections.

\section{Corticostriatal projections from other premotor areas}

A clear-cut finding in our experiments was that the mediolateral position of the medial injections is a major determinant of the distribution of the resulting label in the striatum. When we injected midline cortex of the superior frontal gyrus, medial to the saccade-related zones we mapped out, we found much more transport of tracer to the putamen than when we injected convexity cortex on the dorsal surface of the hemisphere, from which we could elicit saccades on microstimulation. Our results suggest that these shifts in striatal labeling reflect a systematic topography of the corticostriatal projections of the SEF/periSEF and arcuate/periarcuate cortex. The topography of the medial cortical areas appears to correspond to that in the maps of Rizzolatti and colleagues (Luppino et al., 1991), who place a cortical area related to projective body movements in medial area $6 \mathrm{a} \beta$, medial to the cortex from which they were able to evoke saccades. This medial area may correspond to the preSMA of Tanji et al. (1991).

Our evidence also suggests that there are converging corticostriatal inputs to the putamen from the postarcuatc cortex (area 6), including the arcuate premotor area and the SMA or pre-SMA. Neurons in the postarcuate cortex have been reported to have combined visual and tactile receptive fields (Rizzolatti et al., 1981), and the part of the putamen to which the postarcuate cortex projects appears to contain neurons that are similarly responsive (Gross and Graziano, 1990). We did not have sufficient case material to study these inputs in detail, but we did note that when an injection involving one of these cortical areas was paired with an injection in one of the eye fields, the projections did not overlap extensively even though some sets 
of patches from the two injected areas were physically adjacent in the caudate nucleus and medial putamen. This evidence suggests that the premotor and eye field projections are handled as parallel systems; however, the frequent adjacency of the different input patches raises the possibility that the inputs are being brought into proximity in the striatum for cross-patch interactions. Such a functional view would strongly favor the idea that the striatal matrix is organized in patches in part to bring into proximity different cortical signals so that they can be recombined in novel ways (Malach and Graybiel, 1986).

\section{Principles of corticostriatal connectivity}

It is well known that corticostriatal projections from most areas of the cortex form dispersed terminal fields within the striatum (Künzle, 1975, 1977; Goldman and Nauta, 1977; Jones et al., 1977; Yeterian and Van Hoesen, 1978; Ragsdale and Graybiel, 1981; Selemon and Goldman-Rakic, 1985; Flaherty and Graybiel, 1991a). What is novel about our findings in this context is the demonstration that dispersed sets of projection patches from distant cortical sites can converge systematically or, as just discussed, can be adjacent. This evidence suggests that shared mapping rules govern both the widespread dispersion of the patchy inputs from a pair of cortical areas and the local convergence of their two sets of inputs in the striatum.

Our experiments clearly show this patchy, distributed, but convergent organization for FEF and SEF projections to the striatum. In addition, our results suggest similar patterns of overlapping striatal inputs from the medial wall cortex (area $6 \mathrm{a} \beta$ ) and postarcuate cortex. As discussed above, both pairs of cortical areas with converging projections are cortically interconnected. Furthermore, cortically unconnected or weakly connected pairs of areas, including one eye field and cortex adjacent to the other (e.g., the low-threshold FEF and the medial wall cortex) can have corticostriatal projections directed to adjacent sets of striatal sites. Thus, for the cortical regions studied, it appears that cortical connectivity predicts overlap and cortical adjacency predicts adjacency of fiber projections to the striatum.

Several previous attempts have been made to analyze the relationships among different corticostriatal pathways. Experiments with fiber degeneration methods indicated that there was a relatively simple topography of these input pathways governed by the relative physical locations of the cortical areas, with rostral cortical areas projecting rostrally within the striatum and caudal areas projecting more caudally (Kemp and Powell, 1970). Once the more sensitive autoradiographic axon transport methods were developed, it was found that the corticostriatal connections are much more extensive in the anteroposterior dimension than the topographic model suggested (Goldman and Nauta, 1977; but see Saint-Cyr et al., 1990), and the proposal was made that distant but cortically connected areas projected to overlapping regions of the striatum (Yeterian and Van Hoesen, 1978). The first dual-tracer study addressing this issue produced evidence for interdigitation rather than overlap of the projections from cortically interconnected areas (Selemon and Goldman-Rakic, 1985). However, experiments on physiologically identified corresponding sites in different areas of the primate somatic sensory and motor cortex showed that such sites can send convergent projections to the striatum (Flaherty and Graybiel, $1991 \mathrm{~b}$ ) even when they are not heavily interconnected at the cortical level (Jones et al., 1978).

The apparent contradiction in these findings would be resolved if the amount of convergence in the striatum reflects the output organization of the striatum, not just its input organization. The appeal of this proposal is that functionally related inputs would converge, with the degree of functional relatedness being determined by the striatal target. This would allow for activity-dependent sculpting of the convergence patterns. For example, if the signal sent to the superior colliculus via a striatonigro-tectal connection coded for saccades without respect to body movements, it would be reasonable to have converging inputs from cortical eye field zones to the striatal origin of the pathway, but not inputs from the nearby medial and lateral premotor areas encoding nonoculomotor body movements. By contrast, targeting to output channels consolidating somesthetic signals might call for convergence of cortical inputs, for example, deep and cutaneous inputs from areas $3 a$ and $3 b$, respectively, whether the cortical areas are interconnected or not. The fact that the output cells of the striatum, by far the predominant cell type in the striatum, are themselves organized into clusters (Desban et al., 1989; Jiménez-Castellanos and Graybiel, 1989; Giménez-Amaya and Graybiel, 1990; Selemon and GoldmanRakic, 1990) suggests that not just the divergence or convergence of different corticostriatal inputs, but also their patchiness, could reflect the functional output architecture of the striatum.

Several observations from our experiments support the view that the intrinsic architecture of the striatum may influence its afferents. First, we found well-matched dispersion of input patches of fibers originating in pairs of physically separated cortical areas. This suggests that cortical inputs follow striatal cues in terminating in one set of patches in the striatum rather than another. Sccond, we found that the oculomotor and adjoining premotor regions of the frontal lobe, even when projecting densely to a given striatal zone, nevertheless projected only very weakly to the striosomes in that zone, if at all. Third, even though local cortical topography was correlated with the total distributions of the inputs to the striatum (e.g., more anterior and dorsal arcuate cortex projected more anteriorly and dorsally within the striatum than did more posterior arcuate cortex), the degree of overlap of the corticostriatal projections was not readily predicted by the topographic layout of the cortical areas of origin. Clusters of input fibers labeled from medially placed cortical areas overlapped fiber clusters labeled from lateral cortical areas. Taken together, these patterns suggest that cortical inputs to the striatum follow rule systems of at least two types, one relating the degree of input convergence to characteristics of the cortical areas, and another relating input architecture to the local macroscopic organization of the targeted striatal neurons.

\section{References}

Alexander GE, DeLong MR, Strick PL (1986) Parallel organization of functionally segregated circuits linking basal ganglia and cortex. Annu Rev Neurosci 9:357-381.

Bizzi E, Schiller PH (1970) Single unit activity in the frontal eye fields of unanesthetized monkeys. Exp Brain Res 10:151-158.

Boch RA, Goldberg ME (1989) Participation of prefrontal neurons in the preparation of visually guided eye movements in rhesus monkey. J Neurophysiol 61:1064-1084.

Bon I, I ucchetti C (1990) Neurons signalling the maintenance of attentive fixation in frontal area $6 \mathrm{a} \beta$ of the macaque monkey. Exp Brain Res 82:231-233.

Brinkman C (1984) Supplementary motor arca of the monkey's cerebral cortex: short- and long-term deficits after unilateral ablation and the effects of subsequent callosal section. J Neurosci 4:918-929.

Bruce CJ, Goldberg ME (1985) Primate frontal eye fields. I. Single neurons discharging before saccades. J Neurophysiol 53:603-635. 
Camarda R, Luppino G, Matelli M, Rizzolatti G (1991) Cortical connections of two different eye fields in the dorsomedial frontal cortex of the macaque monkey. Soc Neurosci Abstr 17:459.

Chevalier G, Deniau JM (1990) Disinhibition as a basic process in the expression of striatal functions. Trends Neurosci 13:277-280.

Desban M, Gauchy C, Kemel ML, Besson MJ, Glowinski J (1989) Three-dimensional organization of the striosomal compartment and patchy distribution of striatonigral projections in the matrix of the cat caudate nucleus. Neuroscience 29:551-566.

Ferrier D (1875) Experiments on the brain of monkeys. Philos Trans R Soc Lond [Biol] 165:433-488.

Flaherty AW, Graybiel AM (1991a) Corticostriatal transformations in the primate somatosensory system. Projections from physiologically mapped body-part representations. J Neurophysiol 66:12491263.

Flaherty AW, Graybiel AM (1991b) A second input system for body representations in the primate striatal matrix. Soc Neurosci Abstr 17: 1299.

Fox PT, Fox JM, Raichle MW, Burde RM (1985) The role of cerebral cortex in the generation of voluntary saccades: a positron emission tomographic study. J Neurophysiol 54:348-369.

Funahashi S, Bruce CJ, Goldman-Rakic PS (1989) Mnemonic coding of visual space in the monkey's dorsolateral prefrontal cortex. J Neurophysiol 61:331-349.

Gaymard B, Pierrot-Deseilligny C, Rivaud S (1990) Impairment of sequences of memory-guided saccades after supplementary motor area lesions. Ann Neurol 28:622-626.

Giménez-Amaya J-M, Graybiel AM (1990) Compartmental origins of the striatopallidal projection in the primate. Neuroscience 34:111126.

Godaux E, Cheron G, Mettens P (1990) Ketamine induces failure of the oculomotor neural integrator in the cat. Neurosci Lett 116:162167 :

Goldberg ME, Bruce CJ (1990) Primate frontal eye fields. III. Maintenance of a spatially accurate saccade signal. I Neurophysiol 64:489508.

Goldberg ME, Seagraves MA (1989) The visual and frontal cortices. In: The neurobiology of saccadic eye movements, reviews of oculomotor research (Wurtz RH, Goldberg ME, eds), pp 283-313. Amsterdam: Elsevier.

Goldman PS, Nauta WJH (1977) An intricately patterned prefrontocaudate projection in the rhesus monkey. J Comp Neurol 171:369386.

Gould HJ, Cusick CG, Pons TP, Kaas JH (1986) The relationship of corpus callosum connections to electrical stimulation maps of motor, supplementary motor, and the frontal eye fields in owl monkeys. I Comp Neurol 247:297-325.

Graybiel AM (1984) Neurochemically specified subsystems in the basal ganglia. In: Ciba Foundation symposium, Functions of the basal ganglia, pp 114-149. London: Pitman.

Graybiel AM, Chesselet M-F (1984) Compartmental distribution of striatal cell bodies expressing met-enkephalin-like immunoreactivity. Proc Natl Acad Sci USA 81:7980-7984.

Gross CG, Graziano MSA (1990) Bimodal visual-tactile responses in the macaque putamen. Soc Neurosci Abstr 16:110.

Guitton D, Buchtel HA, Douglas RM (1985) Frontal lobe lesions in man cause difficulties in suppressing reflexive glances and in generating goal-directed saccades. Exp Brain Res 58:455-472.

Hikosaka O, Wurtz RH (1983a) Visual and oculomotor functions of monkey Macaca mulatta substantia nigra pars reticulata. 3 . Memory contingent visual and saccade responses. J Neurophysiol 49:12681284.

Hikosaka O, Wurtz RH (1983b) Visual and oculomotor functions of monkey Macaca mulatta substantia nigra pars reticulata. 4 . Relation of substantia nigra to superior colliculus. J Neurophysiol 49:12851301.

Hikosaka O, Wurtz RH (1985a) Modification of saccadic eye movements by gamma aminobutyric-acid-related substances. I. Effect of muscimol and bicuculline in monkey Macaca mulatta superior colliculus. J Neurophysiol 53:266-291.

Hikosaka O, Wurtz RH (1985b) Modification of saccadic eye movements by gamma aminobutyric-acid-related substances. 2 . Effects of muscimol in monkey (Macaca mulatta) substantia nigra pars reticulata. J Neurophysiol 53:292-308.

Hikosaka O, Sakamoto M, Usui S (1989a) Functional properties of monkey caudate neurons. I. Activities related to saccadic eye movements. J Neurophysiol 61:780-798.

Hikosaka O, Sakamoto M, Usui S (1989b) Functional properties of monkey caudate neurons. III. Activities related to expectation of target and reward. J Neurophysiol 61:814-832.

Huerta MF, Kaas JH (1990) Supplementary eye fields as defined by intracortical microstimulation: connections in macaques. J Comp Neurol 293:299-330.

Illing RB, Graybiel AM (1985) Convergence of afferents frontal cortex and substantia nigra onto acetylcholinesterase patches of the cat's superior colliculus. Neuroscience 14:455-482.

Illing RB, Wässle H (1979) Visualization of the HRP reaction product using the polarization microscope. Neurosci Lett 13:7-11.

Jiménez-Castellanos J, Graybiel AM (1989) Compartmental origins of striatal efferent projections in the cat. Neuroscience 32:297-321.

Jones EG, Coulter JD, Burton H, Porter R (1977) Cells of origin and terminal distribution of corticostriatal fibers arising in the sensorymotor cortex of monkeys. J Comp Neurol 173:53-80.

Jones EG, Couter JD, Hendry SHC (1978) Intracortical connectivity of architectonic fields in the somatic sensory, motor and parietal cortex of monkeys. J Comp Neurol 181:291-347.

Joseph JP, Barone P (1987) Prefrontal unit activity during a delayed oculomotor task in the monkey. Exp Brain Res 67:460-468.

Kemp JA, Powell TPS (1970) The cortico-striate projection in the monkey. Brain 93:525-546.

Künzle H (1975) Bilateral projections from precentral motor cortex to the putamen and other parts of the basal ganglia. Brain Res 88: 195-210.

Künzle H (1977) Projections from the primary somatosensory cortex to basal ganglia and thalamus in the monkey. Exp Brain Res 30:481492.

Kurata K, Tanji J (1985) Contrasting neuronal activity in supplementary and precentral motor cortex of monkeys. II. Responses to movement triggering vs. nontriggering sensory signals. J Neurophysiol 53:142-152.

Lee K, Tehovnik EJ (1991) Eye position dependency of units in the dorsomedial frontal cortex. Soc Neurosci Abstr 17:546.

Luppino G, Matelli M, Camarda RM, Gallese V, Rizzolatti G (1991) Multiple representations of body movements in mesial area 6 and the adjacent cingulate cortex: an intracortical microstimulation study in the macaque monkey. J Comp Neurol 311:463-482.

MacAvoy MG, Gottlieb JP, Bruce CJ (1991) Smooth-pursuit eye movement representation in the primate frontal eye field. Cereb Cortex 1:95-102.

Malach R, Graybiel AM (1986) Mosaic architecture of the somatic sensory-recipient sector of the cat's striatum. J Neurosci 6:3436-3458.

Mesulam M-M (1978) Tetramethyl benzidine for horseradish peroxidase neurohistochemistry: a non-carcinogenic blue reaction product with superior sensitivity for visualizing neural afferents and efferents. J Histochem Cytochem 26:106-117.

Mitz AR, Godschalk M (1989) Eye-movement representation in the frontal lobe of rhesus monkeys. Neurosci Lett 106:157-162.

Mitz AR, Wise SP (1987) The somatotopic organization of the supplementary motor area: intracortical microstimulation mapping. $J$ Neurosci 7:1010-1021.

Mushiake H, Inase M, Tanji J (1990) Selective coding of motor sequence in the supplementary motor area of the monkey cerebral cortex. Exp Brain Res 82:208-210.

Percheron G, Filion M (1991) Parallel processing in the basal ganglia: up to a point. Trends Neurosci 14:55-56.

Percheron G, Yelnik J, Francois C (1984) The primate striato-pallidonigral system: an integrative system for cortical information. In: The basal ganglia: structure and function (McKenzie JS, Kemm RE, Wilcock RE, eds), pp 87-105. New York: Plenum.

Ragsdale CW, Graybiel AM (1981) The fronto-striatal projection in the cat and monkey and its relationship to inhomogeneities established by acetylcholinesterase histochemistry. Brain Res 208:259266.

Rizzolatti G, Scandolara C, Matelli M, Gentilucci M (1981) Afferent properties of periarcuate ncurons in macaque monkeys. I. Somatosensory responses. Behav Brain Res 2:125-146.

Robinson DA, Fuchs AF (1969) Eye movements evoked by stimulation of frontal eye fields. J Neurophysiol 32:637-648.

Saint-Cyr JA, Ungerleider LG, Desimone R (1990) Organization of 
visual cortical inputs to the striatum and subsequent outputs to the pallido-nigral complex in the monkey. J Comp Neurol 298:129-156.

Schall JD (1991a) Neuronal activity related to visually guided saccadic eye movements in the supplementary motor area of rhesus monkeys. J Neurophysiol 66:530-558.

Schall JD (1991b) Neuronal activity related to visually guided saccades in the frontal eye fields of rhesus monkeys: comparison with supplementary eye fields. J Neurophysiol 66:559-579.

Schall JD, Morel A, King DJ, Whalley C (1991) Topography of connections between cortical visuomotor areas in the macaque. Soc Neurosci Abstr 17:857.

Schlag J, Schlag-Rey M (1987) Evidence for a supplementary eye field. J Neurophysiol 57:179-200.

Selemon LD, Goldman-Rakic PS (1985) Longitudinal topography and interdigitation of corticostriatal projections in the rhesus monkey. $\mathbf{J}$ Neurosci 5:776-794.

Selemon LD, Goldman-Rakic PS (1990) Topographical intermingling of striatonigral and striatopallidal neurons in the rhesus monkey. J Comp Neurol 297:359-376.

Shook BL, Schlag-Rey M, Schlag J (1991) Primate supplementary eye field. II. Comparative aspects of connections with the thalamus, corpus striatum; and related forebrain nuclei. J Comp Neurol 307:562583.

Snider RS, Lee JC (1961) A stereotaxic atlas of the monkey brain (Macaca mulatta). Chicago: University of Chicago.

Stanton GB, Goldberg ME, Bruce CJ (1988) Frontal eye field efferents in the macaque monkey. I. subcortical pathways and topography of striatal and thalamic terminal fields. J Comp Neurol 271:473-492.

Stanton GB, Deng S-Y, Goldberg ME, McMullen NT (1989) Cytoar- chitectural characteristic of the frontal eye fields in macaque monkeys. J Comp Neurol 282:415-427.

Szabo J, Cowan WM (1984) A stereotaxic atlas of the brain of the cynomolgus monkey (Macaca fascicularis). J Comp Neurol 222:265300.

Tanji J, Aizawa H, Shima K, Matsuzaka Y (1991) A forelimb motor task-related areas rostral to the supplementary motor area. Jpn J Physiol 41:S252.

Tehovnik EJ, Lee K-M (1990) Electrical stimulation of the dorsomedial frontal cortcx (DMFC) of the rhesus monkey. Soc Neurosci Abstr 16:900.

Tomlinson RD, Bahra PS (1986) Combined eye-head gaze shifts in primate. II. Interactions between saccades and the vestibulo-ocular reflex. J Neurophysiol 56:1558-1570.

Vogt O, Vogt C (1919) Ergebnisse unserer Hirnforschung. J Psychol Neurol (Leipzig) 25:277-462.

White OB, Saint-Cyr JA, Tomlinson RD, Sharpe JA (1983) Ocular motor deficits in Parkinson's disease. II. Control of the saccadic and smooth pursuit systems. Brain 106:571-587.

White OB, Saint-Cyr JA, Tomlinson RD, Sharpe JA (1988) Ocular motor deficits in Parkinson's disease. III. Coordination of eye and head movements. Brain 111:115-129.

Woolsey CN, Settlage PH, Meyer DR, Sencer W, Hamuy TP, Travis AM (1952) Patterns of localization in precentral and "supplementary" motor areas and their relation to the concept of a premotor area. Res Publ Assoc Res Nerv Ment Dis 30:238-264.

Yeterian EH, Van Hoesen GW (1978) Cortico-striate projections in the rhesus monkey: the organization of certain cortico-caudate connections. Brain Res 139:43-63. 